Published in final edited form as:

Nat Commun. ; 5: 5586. doi:10.1038/ncomms6586.

\title{
Cerebellar Plasticity and Motor Learning Deficits in a Copy Number Variation Mouse Model of Autism
}

\author{
Claire Piochon ${ }^{1}$, Alexander D Kloth ${ }^{2,3}$, Giorgio Grasselli ${ }^{1}$, Heather K Titley ${ }^{1}$, Hisako \\ Nakayama $^{4}$, Kouichi Hashimoto ${ }^{4}$, Vivian Wan ${ }^{1}$, Dana H Simmons ${ }^{1}$, Tahra Eissa ${ }^{1}$, Jin \\ Nakatani $^{5}$, Adriana Cherskov ${ }^{2,3}$, Taisuke Miyazaki $^{6}$, Masahiko Watanabe ${ }^{6}$, Toru Takumi ${ }^{7}$, \\ Masanobu Kano ${ }^{8}$, Samuel S-H Wang ${ }^{2,3}$, and Christian Hansel ${ }^{1, *}$ \\ ${ }^{1}$ Department of Neurobiology, University of Chicago, Chicago, IL 60637, United States \\ ${ }^{2}$ Department of Molecular Biology, Princeton University, Princeton, NJ 08544, United States \\ ${ }^{3}$ Princeton Neuroscience Institute, Princeton University, Princeton, NJ 08544, United States \\ ${ }^{4}$ Department of Neurophysiology, Institute of Biomedical and Health Sciences, Hiroshima \\ University, Hiroshima 734-8551, Japan
}

${ }^{5}$ Shiga University of Medical Science, Ohtsu 520-2192, Japan

${ }^{6}$ Department of Anatomy, Graduate School of Medicine, Hokkaido University, Sapporo 060-8638, Japan

${ }^{7}$ RIKEN Brain Science Institute, Wako 351-0198, Japan

${ }^{8}$ Department of Neurophysiology, Graduate School of Medicine, The University of Tokyo, Tokyo 113-0033, Japan

\section{Abstract}

\begin{abstract}
A common feature of autism spectrum disorder (ASD) is the impairment of motor control and learning, occurring in a majority of children with autism, consistent with perturbation in cerebellar function. Here we report alterations in motor behavior and cerebellar synaptic plasticity in a mouse model (patDp/+) for the human 15q11-13 duplication, one of the most frequently observed genetic aberrations in autism. These mice show ASD-resembling social behavior deficits. We find that in patDp/+ mice delay eyeblink conditioning — a form of cerebellum-dependent motor learning - is impaired, and observe deregulation of a putative cellular mechanism for motor learning, long-term depression (LTD) at parallel fiber-Purkinje cell synapses. Moreover, developmental elimination of surplus climbing fibers—a model for activity-dependent synaptic
\end{abstract}

\footnotetext{
Users may view, print, copy, and download text and data-mine the content in such documents, for the purposes of academic research, subject always to the full Conditions of use:http://www.nature.com/authors/editorial_policies/license.html\#terms

Correspondence and requests for materials should be addressed to C.H. (chansel@bsd.uchicago.edu).

Author contributions

C.P., M.K., S.S.-H.W., and C.H. conceived and designed the experiments; C.P., A.D.K., G.G., H.K.T., H.N., K.H., V.W., D.H.S., T.E., A.C., T.M., and M.W. performed the experiments; C.P., A.D.K., G.G., H.K.T., H. N., K.H., V.W., D.H.S., T.E., A.C., T.M., and M.W. analyzed the data; J.N., and T.T. contributed reagents/materials/ analysis tools; C.P., M.K., S.S.-H.W., and C.H. wrote the paper.
} 
pruning - is impaired. These findings point to deficits in synaptic plasticity and pruning as potential causes for motor problems and abnormal circuit development in autism.

During recent years, awareness of motor problems in autistic individuals has grown. It has been pointed out that impaired motor coordination is a common feature of autism, which is evident from the fact that $~ 80 \%$ of children with ASD—across a wide range of IQ scoresshow motor impairment ${ }^{1,2}$. Reported motor problems include difficulties with gaze and eye movement control ${ }^{3,4}$. Moreover, abnormalities in delay eyeblink conditioning have been reported in ASD patients ${ }^{5,6}$. Both adaptation of eye movement gains in the vestibulo-ocular reflex (VOR; for review, see refs. 7-9) and delay eyeblink conditioning ${ }^{10}$ are forms of motor learning that require an intact cerebellar system. Thus these findings point towards an involvement of cerebellar dysfunction in ASD symptoms.

Independent evidence for a cerebellar contribution to autism comes from morphological studies. ASD is often associated with abnormalities in cerebellar morphology, such as hypoplasia of the vermis ${ }^{11-13}$, floccular dysplasia ${ }^{14}$ and Purkinje cell degeneration ${ }^{15}$. In fact, changes in cerebellar anatomy are among the most reliable observations in brains from autistic individuals ${ }^{16}$. In agreement with these morphological abnormalities, differences in functional connectivity and activation of cerebellar circuits have been observed using functional magnetic resonance imaging (fMRI) ${ }^{17}$. The hypothesis that the cerebellum plays a role in autism gains further support from an ASD mouse model study, in which Purkinje cell-specific loss of $T s c 1$ (tuberous sclerosis 1; tuberous sclerosis is associated with autism comorbidity) results in both autism-resembling social deficits and ataxia ${ }^{18}$. That study provides the best animal evidence to date that the cerebellum might not only be involved in motor, but also non-motor aspects of autism, and that such a role may exist in rodents as well.

Despite the abundant evidence for cerebellar involvement in ASD, it remains unclear which changes in cerebellar function have a significant behavioral impact. Few cerebellar studies have examined changes in synaptic organization and function, although it has been recognized that synaptopathies play a central role in developmental brain disorders, including autism ${ }^{19}$. To examine which cerebellar synaptic alterations might contribute to motor deficits in autism, we studied cerebellar synaptic function and plasticity as well as motor coordination and learning in a mouse model for the human 15q11-13 duplication. This copy number variation (CNV) is one of the most frequent and most penetrant genetic abnormalities in autism ${ }^{20}$ and is associated with motor problems ${ }^{21,22}$. Cerebellar alterations have previously been described in other ASD mouse models, but these studies either focused on monogenic syndromes such as Fragile X syndrome and TSC that have ASD comorbidity rates of well below $50 \% 18,23$ (for review, see ref. 24), or autism-linked mutations that have been found in only small numbers of affected families (the neuroligin-3 gene Nlgn-3: ref. 25). In contrast, the 15q11-13 duplication is found in 1-3\% of ASD patients ${ }^{26}$-making it the most frequent genetic abnormality in autism - and the penetrance rate in individuals with a maternally derived duplication (see below) is $>85 \% 26,27$. The unusually high penetrance rate of this particular $\mathrm{CNV}$, in combination with the observed motor problems in children with this duplication, makes a mouse model for the 15q11-13 duplication particularly well 
suited to study potential causes for motor impairment in autism. Moreover, maternal deletion of 15q11-13 causes Angelman syndrome, a neurodevelopmental disorder that also is associated with motor abnormalities (e.g. ref. 28, and references cited therein), which stresses the relevance of this location for proper development of both cognitive and motor function.

We found that motor coordination and learning (delay eyeblink conditioning) are impaired in mice with a 15q11-13 duplication, and that a putative cellular correlate of eyeblink conditioning and other forms of motor learning, long-term depression (LTD) at cerebellar parallel fiber (PF) - Purkinje cell synapses ${ }^{29}$, is affected as well. We also used patch-clamp recordings from Purkinje cells during the second postnatal week and from adult Purkinje cells to demonstrate that the elimination of surplus climbing fiber (CF) inputs, a synaptic pruning process critical to the development of cerebellar circuits, is impaired. In summary, our findings a) identify synaptic plasticity deficits in the developing and adult cerebellum as a prominent abnormality in this ASD mouse model for the human 15q11-13 duplication, b) point toward synaptic pathologies that might cause—or contribute to-autism-related problems in motor adaptation and learning, and c) provide leads for the study of synaptic deficits in other parts of the brain that might contribute to specific ASD symptoms.

\section{Results}

\section{ASD mouse model and cerebellar morphology}

The mouse model for the human 15q11-13 duplication used in this study has been previously described ${ }^{20,30}$. In short, chromosome engineering was used to generate a $6.3 \mathrm{Mb}$ interstitial duplication of the conserved linkage group on mouse chromosome 7 (Fig. 1a). Mice with a paternally inherited duplication (patDp/+), but not mice with a maternally inherited duplication (matDp/+), show a reduction in social interaction-seeking behavior, behavioral inflexibility and abnormal ultrasonic vocalization ${ }^{20}$. Thus, these mice display alterations in their behavioral repertoire that —with all caution necessary when comparing behaviors across species-are reminiscent of ASD core symptoms (see also discussion). In humans, the maternally inherited duplication leads to autism ${ }^{21,26}$. Individuals with a paternally inherited duplication can be autistic as well, but the penetrance rate is lower $(\sim 50 \%)^{27}$. A gene located in the $15 \mathrm{q} 11-13$ region that has been linked to autism and is in

both humans and mice maternally expressed is the ubiquitin protein ligase gene $U b e 3 a^{31,32}$, whose maternal deletion causes Angelman syndrome ${ }^{33}$. Using Western blot analysis, we observed that UBE3A is upregulated in the cerebellum of adult patDp/+ mice (Supplementary Fig. 1), showing that changes in the imprinting pattern are also seen at the level of individual genes.

All experiments described were performed using adult patDp/+ mice ( 1-5 months old; unless specified otherwise, see Methods) and wild-type littermate controls. To determine whether cerebellar morphology is altered in patDp/+ mice, sagittal slices obtained from the cerebellum of $\mathrm{patDp} /+$ mice and wild-type littermates were stained with antibodies against calbindin, which marks Purkinje cells in the cerebellum. We did not observe differences in the overall morphology and foliation pattern of the cerebellum (Fig. 1b) or in Purkinje cell density (calculated as number of PCs / length of the Purkinje cell layer [mm]; WT: $28.6 \pm$ 
1.4 cells/mm; $n=4 ;$ patDp/+: $28.6 \pm 0.5$ cells $/ \mathrm{mm} ; \mathrm{n}=4 ; \mathrm{p}=0.98 ;$ Fig. $1 \mathrm{~d}$; see also ref. 20 ). Golgi-stained cerebellar sections were used to examine the morphology of Purkinje cell dendrites (Fig. 1c). We did not find differences in the cumulative length of the dendritic arbor (WT: $3.9 \pm 0.15 \mathrm{~mm} ; \mathrm{n}=10$; patDp/+: $3.6 \pm 0.25 \mathrm{~mm} ; \mathrm{n}=6 ; \mathrm{p}=0.43$; Fig. 1d), the length of the primary dendrite (WT: $334.6 \pm 8.8 \mu \mathrm{m} ; \mathrm{n}=10 ; \mathrm{patDp} /+: 326.1 \pm 15.1 \mu \mathrm{m} ; \mathrm{n}=6 ; \mathrm{p}=0.64$; Fig. 1d), or the complexity of the dendritic arbor as assessed by Sholl analysis (WT: $n=10$; patDp/+: $n=6 ; p=0.82 ;$ Fig. 1e) between patDp/+ mice and wild-type controls. We also used the Golgi-stained sections to determine the thickness of the molecular layer in these mice. We found no difference in this morphological parameter between $\mathrm{patDp} /+$ mice and wildtype littermates (WT: $167.0 \pm 5.5 \mu \mathrm{m} ; \mathrm{n}=22$; patDp/+: $162.7 \pm 4.7 \mu \mathrm{m} ; \mathrm{n}=18 ; \mathrm{p}=0.55$; Fig. 1d). Finally, to examine whether there are differences in the planar organization of Purkinje cell dendrites between patDp/+ mice and wild-type controls, we filled neurons with the fluorescent dye Alexa $633(30 \mu \mathrm{M})$ and obtained 3D-reconstructions of the dendrites using confocal microscopy. We observed both mono- and multiplanar dendrites in wild-type mice (as previously reported; see ref. 34) and patDp/+ mice. To obtain a measure of planarity in Purkinje cell dendrites, we determined the thickness of the dendrites in the coronal dimension (each additional plane enhances this measure ${ }^{34}$ ). We did not observe differences in dendritic thickness (WT: $29.0 \pm 1.9 \mu \mathrm{m} ; \mathrm{n}=23$; patDp/+: $28.9 \pm 3.3 \mu \mathrm{m} ; \mathrm{n}=17 ; \mathrm{p}=0.97$; Supplementary Fig. 2), suggesting that there are no abnormalities in planarity or sagittal orientation in mutant mice. These observations show that the duplication does not impair cerebellar development at large, nor does it affect the proper formation of Purkinje cell dendrites.

\section{Motor coordination and motor learning}

To study whether basic motor coordination is affected in patDp/+ mice, we used the DigiGait imaging system, which provides a detailed analysis of gait and limb movement during treadmill running (Fig. $2 \mathrm{a}+\mathrm{b})$. We observed that in patDp/+ mice $(\mathrm{n}=10)$ locomotion (at $20 \mathrm{~cm} / \mathrm{s})$ is characterized by greater stance width in the forelimbs $(\mathrm{p}=0.03)$, longer stride length (forelimbs: $\mathrm{p}=3 \times 10^{-6}$; hindlimbs: $\mathrm{p}=0.0001$ ), reduced stride frequency (forelimbs: $\mathrm{p}=2 \times 10^{-6}$; hindlimbs: $\mathrm{p}=2 \times 10^{-4}$ ), and enhanced propulsion duration (forelimbs: $\mathrm{p}=5 \times 10^{-8}$; hindlimbs: $p=0.001$ ) compared to wild-type littermate controls ( $n=14$; Fig. 2; Supplementary Table 1). These results indicate that patDp/+ mice, although not ataxic, have altered motor programs to gain stability of locomotion as a result of mild motor impairment.

We next performed delay eyeblink conditioning experiments to examine whether cerebellum-dependent motor learning is affected in patDp/+ mice. Eyeblink conditioning allows for high-precision measurements and quantification, and is sensitive to genetic perturbations in cerebellar signaling ${ }^{35}$. These features make eyeblink conditioning a valuable diagnostic and experimental tool in the study of autism ${ }^{5,6}$. For eyeblink conditioning, mice were head-fixed, but able to walk freely on a fixed-axis rotatable foam cylinder. Eyeblink responses were conditioned using ultraviolet LED light pulses (280ms) as the conditioned stimulus (CS) and co-terminating corneal airpuffs (30ms) as the unconditioned stimulus (US) (Fig. 3a). Eyelid deflection was measured using the Magnetic Distance Measurement Technique (MDMT). After 12 sessions of conditioning (1 session per day; $200 \mathrm{CS}$-US conditioning trials $+20 \mathrm{CS}$ alone test trials per session) patDp/+ mice 
$(\mathrm{n}=10)$ showed significantly fewer CRs than wild-type mice ( $\mathrm{n}=11$; day $12 ; \mathrm{p}=0.0003$; Fig. $3 \mathrm{~d}$ ), indicative of an impairment in a cerebellar learning task (see ref. 23 for comparison).

We tested whether impaired eyeblink conditioning was specific to the learning process itself, as opposed to impairments in the representations of learned blinks. Neither unconditioned responses (UR) nor successful conditioned responses (CR; defined by a closure amplitude of 215\%; see Methods) differed in start time, rise time or peak time between patDp/+ mice and wild-type controls, and the $\mathrm{CR}$ did not differ in amplitude between patDp/+ mice and wildtype controls (Fig. 3b+c; Supplementary Table 2). Thus, once the behavior was initially learned, it was expressed normally. During extinction, patDp/+ mice $(n=10)$ and wild-type controls ( $\mathrm{n}=10)$ did not differ (4 sessions, 1 session per day: $110 \mathrm{CS}$ alone trials +110 US alone trials per session; day $4 ; \mathrm{p}=0.84$ ), nor did they differ during reacquisition ( 3 sessions, 1 session per day: 200 CS-US conditioning trials + 20 CS alone test trials per session; day 3; $\mathrm{p}=0.52$; Fig. 3e). Indeed, we found more CRs when we compared the last day of reacquisition training (Fig. 3e) with the last day of acquisition training (Fig. 3d) in patDp/+ mice $(\mathrm{p}=0.01$; paired two-sample $\mathrm{t}$-test); this was not the case with the wild-type controls $(\mathrm{p}=0.31)$. Thus, impairments in motor learning in $\mathrm{patDp} /+$ mice are specific to de novo acquisition, a process that requires plasticity in the cerebellar cortex, and are not accompanied by deficiencies in blink representation, extinction, or re-acquisition.

\section{Abnormalities in cerebellar synaptic plasticity}

The motor learning deficiency described above is consistent with aberrant plasticity in the cerebellar cortex. LTD and its counterpart long-term potentiation (LTP) at PF - Purkinje cell synapses are activity-dependent forms of synaptic plasticity that in eyeblink conditioning may serve as cellular correlates of CR acquisition and extinction, respectively (for review, see ref. 29). Using whole-cell patch-clamp recordings, we therefore examined LTD and LTP in slices prepared from patDp/+ mice and wild-type littermate controls. These two groups of mice did not differ in basic synaptic response properties, such as PF response amplitude (input-output curve), PF short-term plasticity and the waveform of CF-evoked complex spikes (Supplementary Fig. 3). In the LTD / LTP experiments, we monitored PF-excitatory postsynaptic currents (EPSCs) in voltage-clamp mode during the test periods before and after tetanization. For LTD induction, a train of 8 PF stimuli $(100 \mathrm{~Hz})$ was applied in currentclamp mode, followed $120 \mathrm{~ms}$ after stimulus onset by single-pulse CF stimulation ${ }^{36}$. This pairing protocol was applied at $1 \mathrm{~Hz}$ for $5 \mathrm{~min}$, and elicited LTD in wild-type mice (65.1 \pm $7.1 \%$; $\mathrm{t}=41-45 \mathrm{~min} ; \mathrm{n}=10 ; \mathrm{p}=0.0009 ;$ Fig. 4$)$. In contrast, this protocol triggered a potentiation in slices prepared from patDp/+ mice instead $(123.4 \pm 8.0 \% ; \mathrm{n}=7 ; \mathrm{p}=0.026$; Fig. 4). The EPSC amplitude changes observed in both groups of mice differed significantly from each other ( $\mathrm{p}=0.0011)$. For LTP induction, we applied the same PF burst protocol, but in the absence of CF co-activation ${ }^{36}$. LTP was successfully induced in both wild-type (128.0 $\pm 9.3 \%$; $\mathrm{t}=41-45 \mathrm{~min} ; \mathrm{n}=9 ; \mathrm{p}=0.017 ;$ Fig. 5$)$ and $\mathrm{patDp} /+$ mice $(146.9 \pm 12.6 \% ; \mathrm{n}=5 ; \mathrm{p}=0.02$; Fig. 5). There was no significant difference between the EPSC amplitude changes observed in both groups $(\mathrm{p}=0.28)$. These results reveal a selective impairment of LTD, but not LTP, in patDp/+ mice. 
There are two potential causes for the absence of LTD: a) an impairment of the molecular pathway that triggers LTD, and b) LTD saturation, i.e. synapses are maximally depressed before application of any tetanization protocol. To distinguish between these two possibilities, we applied the LTP protocol first in an effort to un-saturate LTD, and after a stabilization period of $10 \mathrm{~min}$ applied the LTD protocol. In wild-type mice, LTP was induced first (159.8 $\pm 12.4 \%$; $t=16-20 \mathrm{~min} ; \mathrm{n}=9$; $\mathrm{p}=0.0014$; Fig. 6 ). Subsequent application of the LTD protocol caused a depotentiation that significantly depressed EPSCs even when compared to baseline $(83.3 \pm 7.0 \% ; \mathrm{t}=41-45 \mathrm{~min} ; \mathrm{n}=9 ; \mathrm{p}=0.04 ;$ Fig. 6$)$. In patDp/+ mice, EPSCs similarly potentiated first $(151.3 \pm 10.4 \%$; $\mathrm{t}=16-20 \mathrm{~min} ; \mathrm{n}=5 ; \mathrm{p}=0.008$; Fig. 6$)$, and subsequent application of the LTD protocol was indeed able to trigger LTD $(81.3 \pm 6.4 \%$; $\mathrm{t}=41-45 \mathrm{~min} ; \mathrm{n}=5 ; \mathrm{p}=0.04$; Fig. 6). There was no significant difference in LTP $(\mathrm{p}=0.69)$ and LTD amplitudes $(\mathrm{p}=0.89)$ between $\mathrm{pat} \mathrm{p} /+$ mice and wild-type controls. Our findings suggest that, similar to previous observations made in $N \operatorname{lgn} 3^{K O}$ mice ${ }^{25}$, LTD is saturated in patDp/+ mice under baseline conditions, preventing subsequent LTD induction unless the saturation is actively reversed.

\section{Developmental elimination of surplus climbing fibers}

Activity-dependent pruning of synaptic connections during development constitutes an important step in the formation of neural circuits. One of the best-studied examples of activity-dependent synapse / circuit refinement during development is the elimination of surplus CFs in the cerebellum. At birth, Purkinje cells are contacted by three or more CFs, which are eliminated in a competitive manner until—after about three weeks—only one CF input remains in most Purkinje cells ${ }^{37}$. The reduction towards one remaining input represents an extreme example of synaptic pruning, but it is for this reason that it was possible to describe this developmental plasticity phenomenon at this particular synaptic input in great molecular detail. The molecular pathways involved in CF elimination are similar to those required for PF-LTD, including the activation of type 1 metabotropic glutamate receptors (mGluR1) ${ }^{38}$, protein kinase $\mathrm{C}(\mathrm{PKC})^{39}$, and calcium/calmodulindependent kinase II (CaMKII) ${ }^{40}$. To examine whether the elimination of surplus CFs is affected in patDp/+ mice, we determined the number of CF inputs received by Purkinje cells in young patDp/+ mice and wild-type controls (P10-12). For a given Purkinje cell, the number of innervating CF inputs was measured in voltage-clamp mode by counting the number of distinct all-or-none CF-EPSC steps. Extracellular stimulation was applied at 25 locations around the Purkinje cell soma by laterally moving the stimulus electrode, and gradually increasing the stimulus intensity at each location. We found that in $\mathrm{patDp} /+$ mice $16.07 \%$ of Purkinje cells tested received one CF input, $42.86 \%$ received two CF inputs, and $41.07 \%$ received three $\mathrm{CF}$ inputs ( $\mathrm{n}=56$ from six mice; Fig. $7 \mathrm{a}+\mathrm{b}$ ). In wild-type mice $38.18 \%$ of Purkinje cells received one CF input, 50.91\% of Purkinje cells received two CF inputs, and only $10.91 \%$ received three $\mathrm{CF}$ inputs ( $\mathrm{n}=55$ from six mice; Fig. $7 \mathrm{a}+\mathrm{b})$. The distribution of innervation patterns is significantly different between patDp/+ mice and littermate controls ( $\mathrm{p}=0.003$; Mann-Whitney $\mathrm{U}$ test). To examine whether this impairment of $\mathrm{CF}$ elimination persists into adulthood, we also determined the number of $\mathrm{CF}$ inputs received by Purkinje cells in adult patDp/+ mice and wild-type controls (P63-70). We observed that in patDp/+ mice 66.15\% of Purkinje cells received one CF input, 27.69\% received two $\mathrm{CF}$ inputs and $6.15 \%$ received three $\mathrm{CF}$ inputs ( $\mathrm{n}=65$ from five mice; Fig. $7 \mathrm{c}$ 
+ d). In wild-type mice $81.16 \%$ of Purkinje cells received one CF input, $17.39 \%$ received two $\mathrm{CF}$ inputs and $1.45 \%$ received three $\mathrm{CF}$ inputs ( $\mathrm{n}=69$ from five mice; Fig. $7 \mathrm{c}+\mathrm{d}$ ). The distribution of innervation patterns is significantly different between adult patDp/+ mice and littermate controls ( $\mathrm{p}=0.041$; Mann-Whitney $\mathrm{U}$ test). These results (for a breakdown of data by individual mouse, see Supplementary Table 3 ) show that in young patDp/+ mice a significantly higher number of Purkinje cells are innervated by multiple CFs than in wildtype mice, suggesting an impairment of synaptic pruning. The recordings from adult mice suggest that, while $\mathrm{CF}$ elimination occurs in mutant mice, a mild impairment of the pruning process persists into adulthood.

\section{Discussion}

Here, we provide a characterization of motor deficits and cerebellar abnormalities in a mouse model of the 15q11-13 duplication, which is seen in a significant proportion of individuals with autism $(1-3 \%)^{26}$. Motor problems may not be the core issue in autism, but the study of motor behavior (the focus of this investigation) offers significant advantages over the study of social behaviors (not characterized here) when trying to understand how synaptic and circuit abnormalities affect behavioral output. The repertoire of social behaviors is very different between humans and mice, making it difficult to compare or even equate these behaviors. In contrast, some forms of cerebellum-dependent motor learning that involve eye and eyelid movements are less complex, conserved throughout mammalian evolution, and suitable for direct comparison. For example, eyeblink conditioning, which is studied here, is a form of cerebellum-dependent motor learning that is similar across all mammalian species tested to date, including humans ${ }^{41}$. It has been shown that eyeblink conditioning is affected in the general ASD patient population ${ }^{5,6}$ as well as in Fragile X syndrome patients ${ }^{23}$. Eyeblink conditioning might still be of limited clinical relevance, but it is useful as a diagnostic tool, and it also is important as an experimental tool for assessing cerebellar plasticity and motor learning. Our observation that eyeblink conditioning is impaired in patDp/+ mice as well shows that this mouse model, which genetically replicates a known genetic cause for autism (15q11-13 duplication), does not only show social interaction deficits that resemble abnormalities in human autism ${ }^{20}$, but also reflects this ASD-typical motor impairment.

Other motor phenotypes have been tested as well in this mouse model. In an earlier study, it was shown that rotarod learning — a less sensitive motor learning test—is not affected in patDp/+ mice ${ }^{20}$. In contrast, basal motor activity is reduced in these mice ${ }^{30}$. Using the DigiGait imaging system, we examined limb movement coordination on a moving treadmill. We observed that patDp/+ mice use a wider stance in their forelimbs, which may reflect an attempt to gain better stability. The propulsion duration describes the acceleration time. The longer duration of propulsion in the patDp/+ mice may indicate reduced strength and control. We also noted significantly longer stride length and reduced frequency in patDp/+ mice, representing a significant alteration of the motor program. Together, the changes measured in these parameters show mild motor impairment in patDp/+ mice. Unlike eyeblink conditioning, these locomotion-related motor phenotypes cannot be directly compared to motor impairment in humans, but generally correspond to the mild motor problems, as for example evident in clumsiness, that have been reported in 15q11-13 
duplication patients ${ }^{21,22}$. The mouse model does not replicate hypotonia and seizures that have been described in patients with the $15 \mathrm{q}$ duplication syndrome ${ }^{27}$. Nevertheless, the impairment of the evolutionary conserved eyeblink conditioning together with a mild impairment of complex motor coordination indicate that this mouse model is useful for examining how cerebellar dysfunction is generated by the 15q11-13 duplication and how the resulting cerebellar abnormalities may contribute to autism.

Cerebellar dysfunction in ASD has previously been described in three types of genetically modified mice: in mice with a Purkinje cell-specific deletion of $T s c 1^{18}$, mice with a Purkinje cell-specific deletion of the Fragile X mental retardation 1 gene $\mathrm{Fmrl}^{23}$, and $\mathrm{Nlgn}^{\mathrm{KO}}$ mice $^{25}$. The study on Tscl mutant mice demonstrated that a Purkinje cell-specific genetic manipulation results in autism-resembling deficits in social behaviors, late-onset ataxia, and reduced excitability of Purkinje cells ${ }^{18}$. In global Fmrl null mutants, and mice with a Purkinje cell-specific deletion of Fmrl (L7-Fmrl) delay eyeblink conditioning was impaired, and LTD was significantly enhanced ${ }^{23}$. Similarly, enhanced LTD has been observed in the hippocampus of $\mathrm{Fmrl}$ mutant mice ${ }^{42}$. In $N \operatorname{lgn} 3^{\mathrm{KO}}$ mice, eyeblink conditioning has not been assessed, but it was reported that on the Erasmus ladder, a keyboard-resembling device that allows for a rapid withdrawal of 'keys', the occurrence of missteps similarly declined over time in $N \operatorname{lgn} 3^{K O}$ mice and wild-type controls ${ }^{25}$. However, $N \operatorname{lgn} 3^{K O}$ mice showed significantly elevated steptimes on the ladder, indicating a perturbation of motor coordination that resembles the enhanced stride length that we measured in patDp/+ mice on the DigiGait treadmill (Fig. 2). LTD was saturated in $N \operatorname{lgn} 3^{\mathrm{KO}}$ mice, and it was argued that the enhancement of LTD in Fmrl mutant mice ${ }^{23}$ and the saturation of LTD in $N \operatorname{lgn} 3^{K O}$ mice represent the same type of LTD deregulation that prevents a proper LTD - LTP balance required for cerebellar motor learning ${ }^{25}$. The results presented here, which show impairment of eyeblink conditioning and LTD saturation in a mouse model for the human 15q11-13 duplication complement these studies, and together identify deregulation of LTD as a recurring cerebellar abnormality-across ASD mouse models with very different genetic backgrounds - that may explain the impairment in motor learning that is frequently reported. At the same time, our study marks an important step forward in establishing a link between synaptic plasticity deficits and motor problems in autism, because in TSC and Fragile X syndrome well below 50\% of patients meet the diagnostic criteria for autism, and neuroligin mutations have only been characterized in a very limited number of individuals with $\mathrm{ASD}^{43}$. In contrast, the 15q11-13 duplication possibly has the highest penetrance rate in ASD (about $90 \%$ in children with a maternal duplication and $50 \%$ in children with a paternal duplication $)^{27}$, thus enhancing the ASDrelevance of the phenotypic observations.

What are possible consequences of cerebellar LTD deregulation? Can this cerebellar abnormality explain specific ASD symptoms? It has previously been noted that deficits in cerebellar synaptic plasticity do not lead to outright ataxia (see ref. 35). Thus, it does not come as a surprise that we observed mild motor impairment, rather than ataxia in patDp/+ mice. In Marr-Albus-Ito theories of cerebellar function, LTD is seen as a cellular mechanism underlying motor learning ${ }^{44}$. Notably, cerebellar LTD has recently been demonstrated in alert mice, emphasizing the behavioral relevance of this plasticity phenomenon ${ }^{45}$. LTP has 
been described as a potential reversal mechanism ${ }^{29}$. Genetic or pharmacological impairment of LTD (e.g. refs. 40, 46-48) indeed prevents proper motor learning in cerebellumdependent tasks. However, it has been shown that motor learning can remain undisturbed even when LTD is genetically prevented ${ }^{49}$, suggesting that LTD might not be the only mechanism involved. It seems that there are multiple plasticity sites that contribute to a cerebellar memory engram ${ }^{29}, 44,50$ allowing for learning to take place-at least under some circumstances - even if a specific plasticity mechanism fails. For example, a plasticity site downstream of the cerebellar cortex is provided by mossy fiber synapses onto the cerebellar nuclei $^{7,51}$. It is possible that LTP at these synapses ${ }^{52}$ is sufficient for some forms of motor learning even in the absence of LTD at PF synapses. Thus, the available data suggest that LTD is an important plasticity mechanism involved in motor learning, but that other types of plasticity, including plasticity at sites outside the cerebellar cortex, assume important roles in motor learning as well.

While the observations presented here do not allow us to establish causal relationships, our findings fit well to the current understanding of the role of synaptic plasticity in motor learning as outlined above. In this study, we show that in patDp/+ mice LTD is impaired, but that LTD can be rescued after previous LTP induction, suggesting that LTD has been saturated. We also demonstrate that in eyeblink conditioning CR acquisition is impaired, but is restored to normal levels after previous CR extinction. These findings agree with and support the hypothesis that LTD contributes to CR acquisition, while LTP is involved in extinction (see ref. 29). In this scenario, in our experiments application of CS alone causes LTP / CR extinction and enables subsequent CR re-acquisition by un-saturating LTD. Our findings are also in line with the notion that there are plasticity sites other than PF synapses as eyeblink conditioning is reduced, but not absent, in LTD-deficient patDp/+ mice. A remarkable observation is that despite disturbed plasticity, basal PF synaptic transmission is not affected in patDp/+ mice. The same observation has been made in other types of genetically modified mice, in which either LTD or LTP is impaired (e.g. ref. 40). A possible explanation is that in these mice, Purkinje cells can adjust the overall strength of synaptic input using slow compensatory mechanisms, without being able to compensate for the lack of proper fast, activity-dependent plasticity.

It has been suggested that the cerebellum not only controls movement, but is also involved

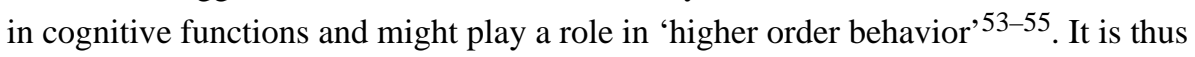
conceivable that cerebellar dysfunction contributes to non-motor symptoms of ASD as well. The recent observation that Purkinje cell-specific deletion of $T s c 1$ replicates autismresembling social behavior deficits supports this claim ${ }^{18}$. The underlying circuit structure enables the cerebellum to act as a learning device that is particularly well suited for associative learning ${ }^{44}$. Cerebellar motor learning is often based on the construction of associations between two sensory inputs (e.g. light-flash and airpuff, or head rotation and retinal slip). The same circuit processes might participate in other forms of learning as well. Thus, dysfunctional cerebellar LTD might well restrict learning-dependent aspects of social behavior, and may contribute to the various manifestations of memory deficits that have been described in autism ${ }^{56}$. In humans and non-human primates, cerebellar projections to non-motor cortical areas, including the prefrontal cortex, have been found, providing an 
anatomical substrate for a cerebellar involvement in non-motor, possibly cognitive processes $^{55,57,58}$.

The LTD deficits observed might be relevant beyond the role of LTD in adult learning: our demonstration of LTD deregulation at cerebellar PF - Purkinje cell synapses may be representative of a broader class of circuit refinement mechanisms throughout the brain. The signaling pathways that trigger LTD show significant overlap with those required for developmental synaptic pruning. Thus LTD provides- to some extent-a read-out for synaptic pruning mechanisms that are crucial for the proper development of neural circuits (for discussion, see ref. 59). The similarity between molecular events that mediate LTD and those that mediate synaptic pruning has been particularly well established in the cerebellum where both LTD and the developmental elimination of surplus CFs — an established model for synaptic pruning - have been extensively studied. Both types of synaptic modification require, for example, the activation of mGluR1 receptors, PLC $\beta 4, \mathrm{PKC}$ as well as $\operatorname{aCaMKII}^{38,40,47,60,61}$ although a dissociation between LTD and CF synaptic pruning might occur at the level of PKC activation as CF elimination is impaired in PKC $\gamma$ mutant mice $^{39}$, while LTD is not affected in these mice ${ }^{62}$. Rather, LTD depends on the activation of $\mathrm{PKCa}^{63}$. Another notable exception is provided by postsynaptically expressed NMDA receptors that play a critical role in $\mathrm{LTD}_{\text {induction }}{ }^{36}$, but have an expression onset that is too late ${ }^{64}$ to be involved in developmental plasticity. LTD has also been found at CF synapses, where it requires the activation of mGluR1 receptors and is blocked by the PKC inhibitor chelerythrine ${ }^{65}$. It has not been tested yet whether NMDA receptors and CaMKII play a role in CF-LTD. Together, these observations suggest a significant, but not complete overlap in molecular mechanisms involved in LTD at PF and CF synapses in the young adult / adult brain and in developmental synapse elimination. In this context, it is interesting to note that cerebellum-dependent motor learning cannot only be impaired when LTD is absent, but also as a result of incomplete CF elimination ${ }^{66}$. Here, we performed patch-clamp recordings from P10-12 and P63-70 Purkinje cells to specifically examine alterations in developmental synaptic pruning. Our findings that $\mathrm{CF}$ elimination is impaired in developing patDp/+ mice and that mild impairment persists into adulthood show that the duplication also affects the developmental formation of neural circuits. Impaired synaptic pruning / LTD across the brain is in line with the hypothesis that autism is characterized by hyperexcitability and hyper-memory (enhanced probability for LTP) ${ }^{67}$ as well as the idea that sensitive-period plasticity may be perturbed in the etiology of $\mathrm{ASD}^{58}$.

A remaining question is how it is possible that LTD is saturated in patDp/+ mice, while CF elimination is incomplete. Observations made in Fmrl mutant mice provide an interesting comparison. These mice show enhanced LTD and reduced eyeblink conditioning performance, similar to the reduced rate of $\mathrm{CR}$ acquisition that we see in patDp/+ mice. However, CF elimination is accelerated ${ }^{23}$. It is possible that enhancement and saturation of LTD similarly affect motor learning, because of the reduced dynamic range for LTD induction. In contrast, it may be due to the similarity in the underlying molecular machinery that alterations in the CF elimination process parallel those seen in LTD and thus CF elimination is accelerated when LTD is enhanced and it is delayed / incomplete when LTD is prevented due to saturation. 
It has previously been noted that LTD is an important read-out for other molecular / synaptic changes in autistic brains. The 'mGluR theory of Fragile X syndrome' resulted from the observation that LTD is significantly altered in Fmrl mutant mice, and it has been pointed out that LTD provides a read-out for local dendritic mRNA translation that occurs in response to mGluR signaling $25,68,69$. The data presented here suggest that, in addition, LTD deregulation might be indicative of associated deficits in synaptic pruning, which is essential for cognitive and affective development. In this view, deficits in synaptic pruning lead to abnormalities in neural circuit formation, which—depending on severity—can explain a wide variety of ASD symptoms.

\section{Methods}

\section{Mouse model and morphological characterization}

For the majority of experiments, we used $~ 1-5$ month-old patDp/+ mice and age-matched littermate controls. In some subgroups of experiments, we used mice from a different age range. The exact age range for each experimental group is specified below. The mouse model for the human 15q11-13 duplication that was studied here has previously been described ${ }^{20}$. In short, an interstitial duplication of mouse chromosome 7 was constructed using chromosome engineering ${ }^{20}$. The mice were backcrossed on a C57BL/6J background for more than 10 generations and were maintained on this genetic background, kept in 12hour light/dark cycles and had access to food and water ad libitum. Both male and female mice were included, except in eyeblink conditioning experiments, for which only males were used. The experiments were performed in accordance with National Institute of Health guidelines and were approved by the Institutional Animal Care and Use Committees of the University of Chicago and Princeton University, as well as the local ethical committees of Hiroshima University, Hokkaido University, the RIKEN Brain Science Institute, and the University of Tokyo, respectively.

For Western blot analysis of UBE3A expression levels, mouse cerebellar tissue was collected after isoflurane anesthesia and was snap-frozen in dry ice. Whole protein extract was obtained from the tissue by Teflon pestle homogenization in 100-200 $\mu$ ice-cold tissue lysis buffer $(50 \mathrm{mM}$ Tris $\mathrm{pH} 7.5,150 \mathrm{mM} \mathrm{NaCl}, 0.5 \%$ Na-Deoxicholate, $1 \%$ Nonidet P-40, $10 \%$ Glycerol, 2\% EDTA, 1\% Sigma-Aldrich protease inhibitor cocktail). The homogenate was centrifuged at $16000 \times \mathrm{g}$ for $15 \mathrm{~min}$ at $4^{\circ} \mathrm{C}$ and the supernatant collected. The protein extracts were quantified for protein concentration by Pierce BCA protein assay kit, divided into aliquots and stored at $-80^{\circ} \mathrm{C}$. An equal amount of $25 \mu \mathrm{g}$ protein extract for each animal was denatured at $95^{\circ} \mathrm{C}$ for $5 \mathrm{~min}$ and loaded on $10 \%$ SDS-polyacrylamide precast gel (Biorad). Gels were blotted on PVDF membranes. Immunodetection was performed by antiUBE3A (mouse, 1:500, for 2 nights; BD Bioscience Cat. 611416), anti- $\beta$-actin (mouse, 1:10,000, over-night; Sigma), horseradish peroxidase conjugated secondary antibodies (goat; Millipore) and ECL-Plus (Amersham) by Chemigenius bioimaging system (Syngene). Exported images were analyzed for densitometric quantification of bands by ImageJ. Values normalized to $\beta$-actin levels were reported as expression level relative to the WT average.

For calbindin immunostaining, mice were deeply anesthetized by ketamine / xylazine and intracardially perfused with ice-cold $4 \%$ paraformaldehyde. Brains were post-fixed for at 
least $2 \mathrm{~h}$ and equilibrated with $30 \%$ sucrose overnight. Sagittal sections $(50 \mu \mathrm{m})$ were permeabilized in PBS with Triton-X $0.25 \%$ (Tx-PBS) and treated as follows in Tx-PBS based solutions: they were pre-incubated with $10 \%$ normal donkey serum solution (Jackson) for $1 \mathrm{~h}$ at RT and incubated with mouse anti-Cb $(1: 1000$; Swant $)$ overnight at $+4^{\circ} \mathrm{C}$, and then incubated with secondary antibody (Alexa 488-conjugated anti-mouse, 1:200; Jackson) for $2 \mathrm{~h}$ at RT and rinsed. For the quantification of PC density, images were acquired with a Zeiss LSM 5 Exciter confocal microscope. Exported images were analyzed by NIH ImageJ software. Calbindin-positive Purkinje cells were counted in random fields (5-7/animal), their number was normalized by the length of the PC layer section that was analyzed and averaged within each animal.

Golgi staining was performed on freshly dissected tissue, obtained from isoflurane anesthetized mice, using a FD Rapid Golgi Stain Kit (FD NeuroTechnologies). Stained slices $(135 \mu \mathrm{m})$ were imaged with a Zeiss AxioCam MRm camera and a 10× IR-Achroplan objective, mounted on a Zeiss Axioscope 2FS microscope (Carl Zeiss MicroImaging). Exported images were analyzed by NIH ImageJ software and NeuronJ plug-in as previously described by Grasselli et al. (2011) ${ }^{70}$ to measure the total length of the dendritic arbor, the thickness of the molecular layer and the length of the primary dendrite. Sholl analysis of dendritic arbors was performed by the Sholl analysis plug-in in ImageJ, counting the number of intersections per radius step with increasing distance from the soma $(5.5 \mu \mathrm{m}$ starting radius; $5.5 \mu \mathrm{m}$ radius steps).

For 3D-reconstruction of Purkinje cell dendrites, neurons were filled with the fluorescent dye Alexa $633(30 \mu \mathrm{M})$. Fluorescent images were acquired using a Zeiss LSM 5 Exciter confocal microscope equipped with $\mathrm{x} 40$ or x63 Apochromat objectives. Fluorescence was excited using a HeNe laser (Lasos Lasertechnik). For reconstruction, confocal serial sections were acquired at $0.7-1.4 \mu \mathrm{m}$ intervals. The z-series was reassembled using Zen software (Carl Zeiss MicroImaging).

\section{DigiGait analysis of motor coordination}

Gait dynamics and locomotion were analyzed using the DigiGait imaging system (version 4.0.0; Mouse Specifics Inc.). Mice were placed on a motorized transparent treadmill within a plexiglass compartment moving at a constant speed of $20 \mathrm{~cm} / \mathrm{s}$ and required to run. Digital videos of paw placement were acquired using a camera mounted beneath the treadmill. The videos were analyzed using DigiGait software (version 12.2), which automatically processes the video images to calculate gait parameters. For each mouse, 2-4 video segments of continuous running ( $3-5$ seconds) were analyzed to obtain an average value for each parameter. The values for left and right paws were averaged.

\section{Delay eyeblink conditioning}

We used a head-restrained version of delay eyeblink conditioning. The test mouse was able to walk on a stationary foam cylinder, while its head was mounted in the apparatus by a titanium headplate that was surgically attached to the skull. A biologically neutral conditioned stimulus (CS: ultraviolet LED, 280ms) was presented to the animal such that it co-terminated with the presentation of the unconditioned stimulus (US: corneal airpuff 
through a 27-gauge needle, 15-20psi, 30ms, see Fig. 3a). Both stimuli were delivered close enough to the animal's head to elicit smooth eyelid responses with training. The eyelid deflection was measured by a Hall-effect magnetic sensor that detected the magnetic field that was induced by a magnet that was surgically attached to the animal's lower eyelid as it moved closer to the sensor. The output of this sensor was sampled at $1 \mathrm{kHz}$ using a National Instruments data acquisition system, providing sufficient resolution to analyze the magnitude and latency of the eyelid deflection. We used the following training scheme: 12 days of acquisition training (200 CS-US pair trials +20 CS-alone trials per day), followed by 4 days of extinction training (110 CS-alone trials +110 US-alone trials per day),

followed by 3 days of reacquisition training (200 CS-US pair trials +20 CS-alone trials per day). The minimum inter-trial interval was 12 seconds; as trials were only presented to the mice when the eyelid was sufficiently open (relative to calibration puffs delivered at the beginning of the training session) and stable for one second prior to stimulus onset, the intertrial interval between any two trials was typically longer than 12 seconds. On any given trial, a response was only counted as a 'conditioned response' (CR) when the amplitude exceeded $15 \%$ of the range between baseline and the amplitude of the unconditioned response (UR) during the period from $100 \mathrm{~ms}$ after CS onset to CS offset. The performance was calculated from the number of successful CRs per experimental session. For CRs, kinetics parameters (start time, rise time, peak time) were calculated from responses to unpaired CSs during the training session and the amplitude was calculated relative to the peak amplitude of the UR on the most recent CS-US pairing. For URs, kinetics parameters (start time, rise time, peak time) were calculated from responses to unpaired USs during the first training session.

\section{Patch-clamp recordings from cerebellar slices}

Slice preparation-Sagittal slices of the cerebellar vermis $(200$ or $250 \mu \mathrm{m})$ were prepared from patDp/+ mice and wild-type littermate controls after isoflurane anesthesia and decapitation. Slices were cut using a vibratome (Leica VT1000S and VT1200S) equipped with ceramic or stainless steel blades. Slice preparation was performed at $4^{\circ} \mathrm{C}$ in artificial cerebrospinal fluid (ACSF) containing the following (in $\mathrm{mM}$ ): $124 \mathrm{NaCl}, 5 \mathrm{KCl}, 1.25$ $\mathrm{Na}_{2} \mathrm{HPO}_{4}, 2 \mathrm{MgSO}_{4}, 2 \mathrm{CaCl}_{2}, 26 \mathrm{NaHCO}_{3}$ and $10 \mathrm{D}$-glucose, bubbled with $95 \% \mathrm{O}_{2}$ and $5 \% \mathrm{CO}_{2}$ (pH 7.4). For the experiments shown in Supplementary Fig. 3a+b and Fig. 7, the ACSF contained the following (in mM): $125 \mathrm{NaCl}, 2.5 \mathrm{KCl}, 1.25 \mathrm{NaH}_{2} \mathrm{PO}_{4}, 1 \mathrm{MgSO}_{4}, 2$ $\mathrm{CaCl}_{2}, 26 \mathrm{NaHCO}_{3}$ and $20 \mathrm{D}$-glucose, bubbled with $95 \% \mathrm{O}_{2}$ and $5 \% \mathrm{CO}_{2}(\mathrm{pH}$ 7.4).

Subsequently, slices were transferred to a storage chamber where they were kept for at least one hour in ACSF at room temperature. For experiments, slices were transferred to a recording chamber that was continuously perfused with ACSF that was supplemented with picrotoxin $(100 \mu \mathrm{M})$ or bicuculline $(10 \mu \mathrm{M})$ to block $\mathrm{GABA}_{\mathrm{A}}$ receptors. All chemicals and drugs were purchased from Sigma-Aldrich (St. Louis, MO).

Electrophysiology-Whole-cell patch-clamp recordings from the Purkinje cell soma were performed at room temperature (the recordings shown in Supplementary Fig. 3a+b and Fig. 7 were performed at $32^{\circ} \mathrm{C}$ ) using an EPC-10 amplifier (HEKA Electronics). Currents were filtered at $3 \mathrm{kHz}$, digitized at $25 \mathrm{kHz}$ or $50 \mathrm{kHz}$, and acquired using Patchmaster or Pulse software (HEKA Electronics). Patch pipettes (2-5M $\Omega$, borosilicate glass) were filled with a solution containing (in mM): $120 \mathrm{~K}$-gluconate, $9 \mathrm{KCl}, 10 \mathrm{KOH}$, $10 \mathrm{HEPES}, 3.48 \mathrm{MgCl}_{2}, 4$ 
$\mathrm{NaCl}, 4 \mathrm{Na}_{2} \mathrm{ATP}, 0.4 \mathrm{Na}_{3} \mathrm{GTP}$, and 17.5 sucrose ( $\mathrm{pH}$ 7.25-7.35). Purkinje cells were voltage-clamped at a holding potential of $-70 \mathrm{mV}$. Liquid junction potentials were not corrected. Fast and slow capacitances were compensated and series resistance was partially compensated (50-80\%). For synaptic activation, glass pipettes filled with ACSF were used. For PF stimulation, electrodes were placed in the upper molecular level to reduce the risk of unintentional CF activation. For CF stimulation, electrodes were placed in the granule cell layer, just underneath the recorded Purkinje cells. LTD and LTP induction protocols were applied at $1 \mathrm{~Hz}$ for $5 \mathrm{~min}$ in current-clamp mode. For LTD induction, $100 \mathrm{~Hz}$ PF stimulation (8 pulses) was followed $120 \mathrm{~ms}$ after stimulus onset by single-pulse CF stimulation. For LTP induction, $100 \mathrm{~Hz}$ PF stimulation (8 pulses) was applied in isolation. It has previously been demonstrated that these protocols trigger postsynaptically expressed forms of LTD and LTP, respectively ${ }^{36}$. Series and input resistance were monitored throughout the experiments by applying hyperpolarizing voltage steps $(-10 \mathrm{mV})$ at the end of each sweep. Recordings were excluded if series or input resistances varied $>15 \%$ over the course of the experiments. All values were averaged over time (three successive responses recorded at 20s-intervals) and are shown as $\%$ of baseline \pm SEM (calculated from $5 \mathrm{~min}$ of baseline recordings). To determine the number of CFs innervating Purkinje cells in P10-12 and P63-70 mice, the patch pipette saline consisted of (in $\mathrm{mM}$ ): $60 \mathrm{CsCl}, 10 \mathrm{Cs}$ D-gluconate, 20 TEA-Cl, 20 BAPTA, $4 \mathrm{MgCl}_{2}$, $4 \mathrm{Na}_{2} \mathrm{ATP}, 0.4 \mathrm{Na}_{3} \mathrm{GTP}$, and 30 HEPES (pH 7.3, adjusted with $\mathrm{CsOH}$ ). The number of $\mathrm{CF}$ inputs was determined in voltage-clamp mode by counting the number of all-or-none CF-EPSC steps that were evoked by gradually increasing stimulus intensity at five or more locations around the Purkinje cell soma.

\section{Mouse age ranges for the different experimental groups}

A) Calbindin stainings (Fig. 1B): 1 month. B) Golgi stainings (Fig. 1C-E): 2-7 months. C) DigiGait analysis (Fig. 2): 1.3 - 2.4 months. D) Eyeblink conditioning (Fig. 3): 2-3 months. E) Patch-clamp recordings from cerebellar slices (Figs. 4-6; Suppl. Fig. S3): 3.5 weeks -5 months. F) Developmental CF elimination (Fig. 7): P10-12 and P63-70. G) Western blot analysis of UBE3A expression levels (Suppl. Fig. S1): 3-13 months. H) 3D-reconstruction of Alexa 633-filled dendrites (Suppl. Fig. S2): 2-5 months. With the exception of the CF elimination experiments, we performed all experiments at an age at which synaptic maturation is typically complete (>P21) and onwards into adulthood. The exact age range used depended on mouse availability. In order to assess and correct for possible age-related differences between wild-type and patDp/+ mice, we performed an analysis of covariance using age as a covariant, followed by post-hoc Tukey's tests (with the exception of CF elimination data). All statistical differences outlined in the Results section were confirmed in this post-hoc analysis (Supplementary Table 4).

\section{Data analysis}

For DigiGait analysis we used an unpaired t-test to determine significance. For eyeblink conditioning, groupwise differences across training sessions were analyzed using a repeatedmeasures two-way ANOVA with genotype and training session as factors. For statistical analyses of conditioned and unconditioned response parameters two-sample t-tests were used. For analysis of morphological parameters, we used an unpaired t-test. For Sholl analysis of dendritic complexity, we used a repeated-measures two-way ANOVA with 
genotype and radius as factors. All other hypothesis testing used the paired Student's t-test (within-group comparison of paired events) and the Mann-Whitney U test (between-group comparison), when appropriate. Electrophysiological data were analyzed using PatchMaster or Pulse Fit software (HEKA Electronics) and Igor Pro software (Wavemetrics). Imaging data were analyzed using ZEN software (Carl Zeiss MicroImaging). All data are shown as mean \pm SEM.

\section{Supplementary Material}

Refer to Web version on PubMed Central for supplementary material.

\section{Acknowledgements}

We would like to thank E. H. Cook and P. Mason for helpful suggestions and for critically reading the manuscript. This work was supported by Ministry of Education, Culture, Sports, Science and Technology in Japan Grants-inAid for Scientific Research (25242077 and 23111005 to T. T.; 25123716 and 25117006 to K.H.; 2420007 to M.W.; 25000015 to M.K.), and the Ministry's Strategic Research Program for Brain Sciences (M.K.), CREST from the Japanese Science and Technology Agency (T.T.), MEXT, Japan (M.K.), the Global COE Program (M.K.), a grant from the Nancy Lurie Marks Family Foundation (S.S.-H.W.), National Institutes of Health grants NS045193 (S.S.H.W.) and F31 MH098651 (A.K.), Simons Foundation grants SFARI 221582 (S.S.-H.W.), SFARI 203507 and SFARI 311232 (C.H.), and a grant from the Brain Research Foundation BRF SG 2011-07 (C.H.).

\section{References}

1. Green D, et al. Impairment in movement skills of children with autistic spectrum disorders. Dev. Med. Child Neurol. 2009; 51:311-316. [PubMed: 19207298]

2. Fournier KA, Hass CJ, Naik SK, Lodha N, Cauraugh JH. Motor coordination in autism spectrum disorders: a synthesis and meta-analysis. J. Autism Dev. Disord. 2010; 40:1227-1240. [PubMed: 20195737]

3. Johnson BP, Rinehart N, White O, Millist L, Fielding J. Saccade adaptation in autism and Asperger's disorder. Neuroscience. 2013; 243:76-87. [PubMed: 23562581]

4. Mosconi MW, et al. Saccade adaptation abnormalities implicate dysfunction of cerebellar-dependent learning mechanisms in autism spectrum disorders (ASD). PLoS One. 2013; 8:e63709. [PubMed: 23704934]

5. Sears LL, Finn PR, Steinmetz JE. Abnormal classical eye-blink conditioning in autism. J. Autism Dev. Disord. 1994; 24:737-751. [PubMed: 7844097]

6. Oristaglio J, et al. Children with autism spectrum disorders show abnormal conditioned response timing on delay, but not trace, eyeblink conditioning. Neuroscience. 2013; 248:708-718. [PubMed: 23769889]

7. Miles FA, Lisberger SG. Plasticity in the vestibulo-ocular reflex: a new hypothesis. Ann. Rev. Neurosci. 1981; 4:273-299. [PubMed: 6784658]

8. Ito M. Cerebellar control of the vestibulo-ocular reflex-around the flocculus hypothesis. Ann. Rev. Neurosci. 1982; 5:275-298. [PubMed: 6803651]

9. Boyden ES, Katoh A, Raymond JL. Cerebellum-dependent learning: the role of multiple plasticity mechanisms. Ann. Rev. Neurosci. 2004; 27:581-609. [PubMed: 15217344]

10. McCormick DA, Thompson RF. Cerebellum: essential involvement in the classically conditioned eyelid response. Science. 1984; 223:296-299. [PubMed: 6701513]

11. Courchesne E. Brainstem, cerebellar and limbic neuroanatomical abnormalities in autism. Curr. Opin. Neurobiol. 1997; 7:269-278. [PubMed: 9142760]

12. Carper RA, Courchesne E. Inverse correlation between frontal lobe and cerebellum sizes in children with autism. Brain. 2000; 123:836-844. [PubMed: 10734014]

13. Kaufmann WE, et al. Specificity of cerebellar vermian abnormalities in autism: a quantitative magnetic resonance imaging study. J. Child Neurol. 2003; 18:463-470. [PubMed: 12940651] 
14. Wegiel J, et al. Contribution of olivofloccular circuitry developmental defects to atypical gaze in autism. Brain Res. 2013; 1512:106-122. [PubMed: 23558308]

15. Palmen SJ, van Engeland H, Hof PR, Schmitz C. Neuropathological findings in autism. Brain. 2004; 127:2572-2583. [PubMed: 15329353]

16. Fatemi SH, et al. Consensus paper: pathological role of the cerebellum in autism. Cerebellum. 2012; 11:777-807. [PubMed: 22370873]

17. Mostofsky SH, et al. Decreased connectivity and cerebellar activity in autism during motor task performance. Brain. 2009; 132:2413-2425. [PubMed: 19389870]

18. Tsai PT, et al. Autistic-like behavior and cerebellar dysfunction in Purkinje cell Tscl mutant mice. Nature. 2012; 488:647-651. [PubMed: 22763451]

19. Grant SG. Synaptopathies: diseases of the synaptome. Curr. Opin. Neurobiol. 2012; 22:522-529. [PubMed: 22409856]

20. Nakatani J, et al. Abnormal behavior in a chromosome-engineered mouse model for human 15q11-13 duplication seen in autism. Cell. 2009; 137:1235-1246. [PubMed: 19563756]

21. Cook EH, et al. Autism or atypical autism in maternally but not paternally derived proximal $15 \mathrm{q}$ duplication. Am. J. Hum. Genet. 1997; 60:928-934. [PubMed: 9106540]

22. Bolton PF, et al. The phenotypic manifestations of interstitial duplications of proximal $15 \mathrm{q}$ with special reference to the autistic spectrum disorders. Am. J. Med. Genet. 2001; 105:675-685. [PubMed: 11803514]

23. Koekkoek SK, et al. Deletion of FMR1 in Purkinje cells enhances parallel fiber LTD, enlarges spines, and attenuates cerebellar eyelid conditioning in Fragile X syndrome. Neuron. 2005; 47:339-352. [PubMed: 16055059]

24. Abrahams BS, Geschwind DH. Advances in autism genetics: on the threshold of a new neurobiology. Nat. Rev. Genet. 2008; 9:341-355. [PubMed: 18414403]

25. Baudouin SJ, et al. Shared synaptic pathophysiology in syndromic and nonsyndromic rodent models of autism. Science. 2012; 338:128-132. [PubMed: 22983708]

26. Cook EH, Scherer SW. Copy-number variations associated with neuropsychiatric conditions. Nature. 2008; 455:919-923. [PubMed: 18923514]

27. Urraca $\mathrm{N}$, et al. The interstitial duplication 15q11.2-q13 syndrome includes autism, mild facial anomalies and a characteristic EEG signature. Autism Res. 2013; 6:268-279. [PubMed: 23495136]

28. Heck DH, Zhao Y, Roy S, LeDoux MS, Reiter LT. Analysis of cerebellar function in Ube3adeficient mice reveals novel genotype-specific behaviors. Hum. Mol. Genet. 2008; 17:2181-2189. [PubMed: 18413322]

29. Jörntell H, Hansel C. Synaptic memories upside down: bidirectional plasticity at cerebellar parallel fiber-Purkinje cell synapses. Neuron. 2006; 52:227-238. [PubMed: 17046686]

30. Tamada K, et al. Decreased exploratory activity in a mouse model of $15 \mathrm{q}$ duplication syndrome; implications for disturbance of serotonin signaling. PLoS One. 2010; 5:e15126. [PubMed: 21179543]

31. Albrecht U, et al. Imprinted expression of the murine Angelman syndrome gene, Ube $3 a$, in hippocampal and Purkinje neurons. Nat. Genet. 1997; 17:75-78. [PubMed: 9288101]

32. Smith SE, et al. Increased gene dosage of Ube 3 a results in autism traits and decreased glutamate synaptic transmission in mice. Science Transl. Med. 2011; 3:103ra97.

33. Matsuura T, et al. De novo truncating mutations in E6-AP ubiquitin-protein ligase gene (UBE3A) in Angelman syndrome. Nat. Genet. 1997; 15:74-77. [PubMed: 8988172]

34. Kaneko M, et al. Remodeling of monoplanar Purkinje cell dendrites during cerebellar circuit formation. PLoS One. 2011; 6:e20108. [PubMed: 21655286]

35. Rinaldo L, Hansel C. Ataxias and cerebellar dysfunction: involvement of synaptic plasticity deficits? Funct. Neurol. 2010; 25:135-139. [PubMed: 21232209]

36. Piochon C, Levenes C, Ohtsuki G, Hansel C. Purkinje cell NMDA receptors assume a key role in synaptic gain control in the mature cerebellum. J. Neurosci. 2010; 30:15330-15335. [PubMed: 21068337] 
37. Crépel F, Mariani J, Delhaye-Bouchaud N. Evidence for a multiple innervation of Purkinje cells by climbing fibers in the immature rat cerebellum. J. Neurobiol. 1976; 7:567-578. [PubMed: 1003202]

38. Kano M, et al. Persistent multiple climbing fiber innervation of cerebellar Purkinje cells in mice lacking mGluR1. Neuron. 1997; 18:71-79. [PubMed: 9010206]

39. Kano M, et al. Impaired synapse elimination during cerebellar development in PKC $\gamma$ mutant mice. Cell. 1995; 83:1223-1231. [PubMed: 8548808]

40. Hansel C, et al. aCaMKII is essential for cerebellar LTD and motor learning. Neuron. 2006; 51:835-843. [PubMed: 16982427]

41. Fanselow MS, Poulos AM. The neuroscience of mammalian associative learning. Annu. Rev. Psychol. 2005; 56:207-234. [PubMed: 15709934]

42. Huber KM, Gallagher SM, Warren ST, Bear MF. Altered synaptic plasticity in a mouse model of fragile X mental retardation. Proc. Natl. Acad. Sci. USA. 2002; 99:7746-7750. [PubMed: 12032354]

43. Zoghbi HY, Bear MF. Synaptic dysfunction in neurodevelopmental disorders associated with autism and intellectual disabilities. Cold Spring Harb. Persp. Biol. 2012; 4:a009886.

44. Ito M, Yamaguchi K, Nagao S, Yamazaki T. Long-term depression as a model of cerebellar plasticity. Prog. Brain Res. 2014; 210:1-30. [PubMed: 24916287]

45. Marquez-Ruiz J, Cheron G. Sensory stimulation-dependent plasticity in the cerebellar cortex of alert mice. PLoS One. 2012; 7:e36184. [PubMed: 22563448]

46. Aiba A, et al. Deficient cerebellar long-term depression and impaired motor learning in mGluR1 mutant mice. Cell. 1994; 79:377-388. [PubMed: 7954803]

47. De Zeeuw CI, et al. Expression of a protein kinase C inhibitor in Purkinje cells blocks cerebellar LTD and adaptation of the vestibulo-ocular reflex. Neuron. 1998; 20:495-508. [PubMed: 9539124]

48. Titley HK, Heskin-Sweezie R, Broussard DM. The bidirectionality of motor learning in the vestibulo-ocular reflex is a function of cerebellar mGluR1 receptors. J. Neurophysiol. 2010; 104:3657-3666. [PubMed: 20926606]

49. Schonewille M, et al. Reevaluating the role of LTD in cerebellar motor learning. Neuron. 2011; 70:43-50. [PubMed: 21482355]

50. Gao Z, van Beugen BJ, De Zeeuw CI. Distributed synergistic plasticity and cerebellar learning. Nat. Rev. Neurosci. 2012; 13:619-635. [PubMed: 22895474]

51. Ohyama T, Nores WL, Medina JF, Riusech FA, Mauk MD. Learning-induced plasticity in deep cerebellar nucleus. J. Neurosci. 2006; 26:12656-12663. [PubMed: 17151268]

52. Pugh JR, Raman IM. Mechanisms of potentiation of mossy fiber EPSCs in the cerebellar nuclei by coincident synaptic excitation and inhibition. J. Neurosci. 2008; 28:10549-10560. [PubMed: 18923031]

53. Schmahmann JD. An emerging concept. The cerebellar contribution to higher function. Arch. Neurol. 1991; 48:1178-1187. [PubMed: 1953406]

54. Schmahmann JD. Disorders of the cerebellum: ataxia, dysmetria of thought, and the cerebellar cognitive affective syndrome. J. Neuropsych. Clin. Neurosci. 2004; 16:367-378.

55. Buckner RL. The cerebellum and cognitive function: 25 years of insight from anatomy and neuroimaging. Neuron. 2013; 80:807-815. [PubMed: 24183029]

56. Williams DL, Goldstein G, Minshew NJ. The profile of memory function in children with autism. Neuropsychol. 2006; 20:21-29.

57. Bostan AC, Dum RP, Strick PL. Cerebellar networks with the cerebral cortex and basal ganglia. Trends Cogn. Sci. 2013; 17:241-254. [PubMed: 23579055]

58. Wang SSH, Kloth AD, Badura A. The cerebellum, sensitive periods, and autism. Neuron. 2014; 83:518-532. [PubMed: 25102558]

59. Hansel, C.; Bear, MF. LTD-synaptic depression and memory storage. In: Sweatt, JD.; Byrne, John, editors. Molecular mechanisms of memory. Vol. [4] of Learning and memory: a comprehensive reference, 4 vols. Oxford: Elsevier; 2008. p. 327-366. 
60. Kano M, et al. Phospholipase C $\beta 4$ is specifically involved in climbing fiber synapse elimination in the developing cerebellum. Proc. Natl. Acad. Sci. USA. 1998; 95:15724-15729. [PubMed: 9861037]

61. Miyata M, et al. Deficient long-term synaptic depression in the rostral cerebellum correlated with impaired motor learning in phospholipase C $\beta 4$ mutant mice. Eur. J. Neurosci. 2001; 13:19451954. [PubMed: 11403688]

62. Chen $\mathrm{C}$, et al. Impaired motor coordination correlates with persistent multiple climbing fiber innervation in PKC $\gamma$ mutant mice. Cell. 1995; 83:1233-1242. [PubMed: 8548809]

63. Leitges M, Kovac J, Plomann M, Linden DJ. A unique PDZ ligand in PKCa confers induction of cerebellar long-term depression. Neuron. 2004; 44:585-594. [PubMed: 15541307]

64. Piochon C, et al. NMDA receptor contribution to the climbing fiber response in the adult mouse Purkinje cell. J. Neurosci. 2007; 27:10797-10809. [PubMed: 17913913]

65. Hansel C, Linden DJ. Long-term depression of the cerebellar climbing fiber-Purkinje neuron synapse. Neuron. 2000; 26:473-482. [PubMed: 10839365]

66. Kimpo RR, Raymond JL. Impaired motor learning in the vestibulo-ocular reflex in mice with multiple climbing fiber input to cerebellar Purkinje cells. J. Neurosci. 2007; 27:5672-5682. [PubMed: 17522312]

67. Markram H, Rinaldi T, Markram K. The Intense World Syndrome - an alternative hypothesis for autism. Front. Neurosci. 2007; 1:77-96. [PubMed: 18982120]

68. Bear MF, Huber KM, Warren ST. The mGluR theory of fragile X mental retardation. Trends in Neurosci. 2004; 27:370-377.

69. Auerbach BD, Osterweil EK, Bear MF. Mutations causing syndromic autism define an axis of synaptic pathophysiology. Nature. 2011; 480:63-68. [PubMed: 22113615]

70. Grasselli G, Mandolesi G, Strata P, Cesare P. Impaired sprouting and axonal atrophy in cerebellar climbing fibers following in vivo silencing of the growth-associated protein GAP-43. PLoS One. 2011; 6:e20791. [PubMed: 21695168] 
a
HSA $15 \quad$ MMU 7

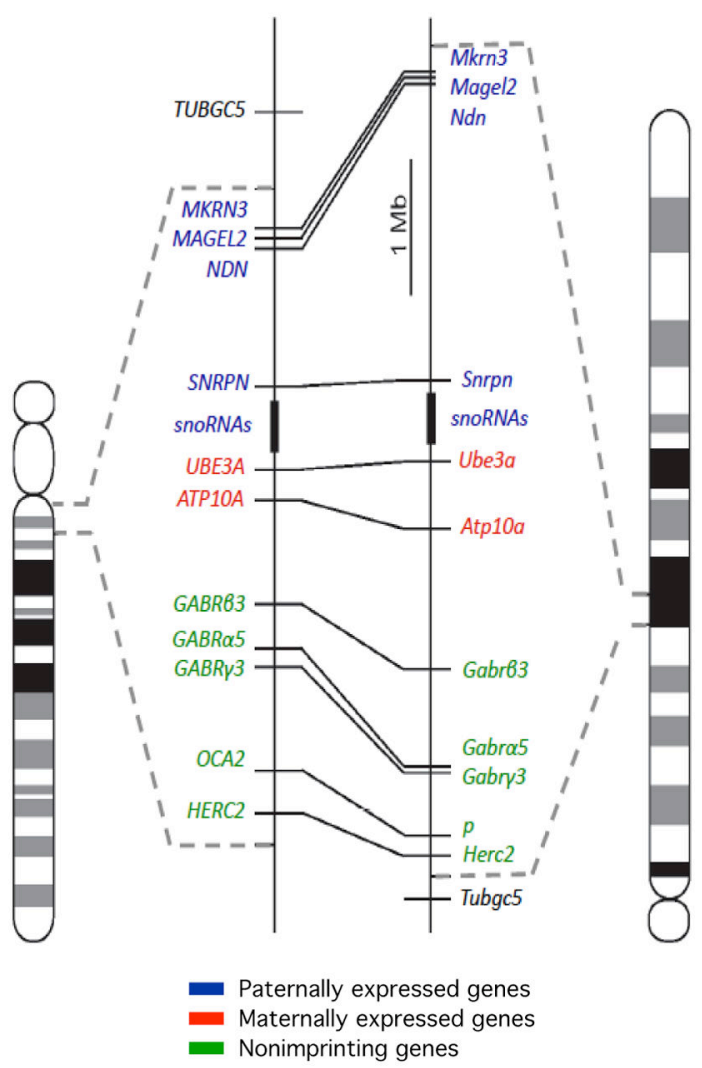

b
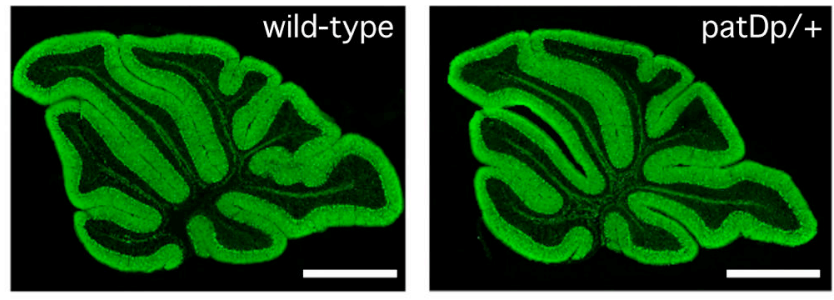

C
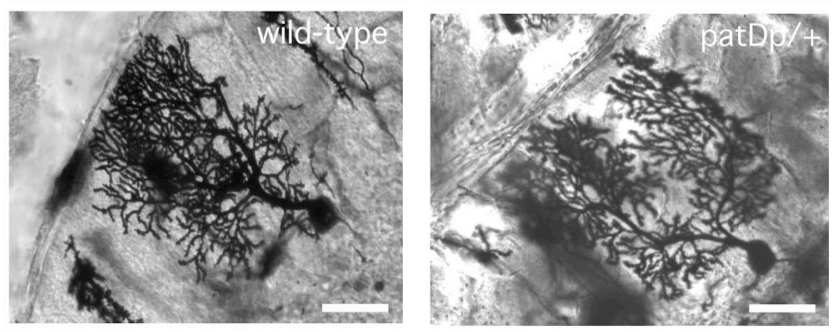

- wild-type patDp/+
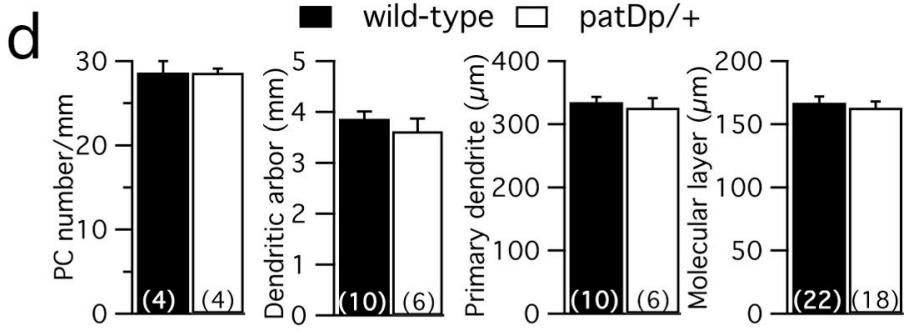

e
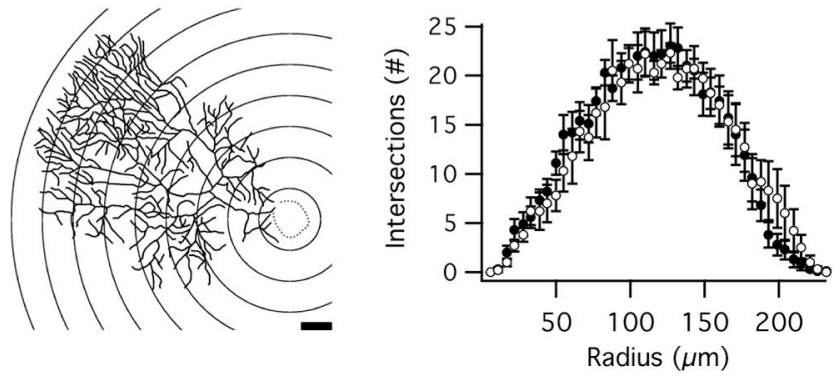

Figure 1. Cerebellar morphology is comparable in patDp/+ and wild-type mice (a) Schematic representation of the corresponding regions of human chromosome 15 (left) and mouse chromosome 7 (right). Conserved linkage groups are shown by connecting lines between the human and mouse chromosomes. Genes that in wild-type mice are paternally expressed, maternally expressed, and non-imprinting genes are labeled with blue, red and green, respectively. Dotted lines indicate the borders of the duplication regions. (b) Calbindin stainings of sagittal cerebellar sections obtained from wild-type (left) and patDp/+ mice (right). Scale bar $=1 \mathrm{~mm}$. (c) Golgi staining of Purkinje cells in wild-type (left) and patDp/+ mice (right). Scale bar $=50 \mu \mathrm{m}(\mathbf{d})$ Bar graphs showing that there were no differences (unpaired Student's t-test) in Purkinje cell density ( $\mathrm{p}=0.98$ ), cumulative length of the dendritic arbor $(\mathrm{p}=0.43)$, length of the primary dendrite $(\mathrm{p}=0.64)$ and thickness of the molecular layer $(\mathrm{p}=0.55)$, respectively, between wild-type and $\mathrm{patDp} /+$ mice. The numbers in brackets indicate the number of Purkinje cells/number of mice tested. (e) Sholl analysis. Left: schematic representation of the analysis method. $22 \mu \mathrm{m}$ radius steps are shown for illustration. The Purkinje cell shown corresponds to the wild-type Purkinje cell in (c). Scale bar: $20 \mu \mathrm{m}$. The quantification of dendritic branching was performed based on reconstructed 
Golgi-stained Purkinje cells. Right: number of intersections of the dendrite at different distances (radius, as indicated by the rings shown on the left) from the soma (center of analysis). A repeated-measures ANOVA indicates no significance for genotype $\left(\mathrm{F}_{1,38}=0.0538, \mathrm{p}=0.82\right)$ and radius $*$ genotype interaction $\left(\mathrm{F}_{1,38}=0.5257, \mathrm{p}=0.99\right)$ Values are shown as mean \pm SEM. 
a wild-type
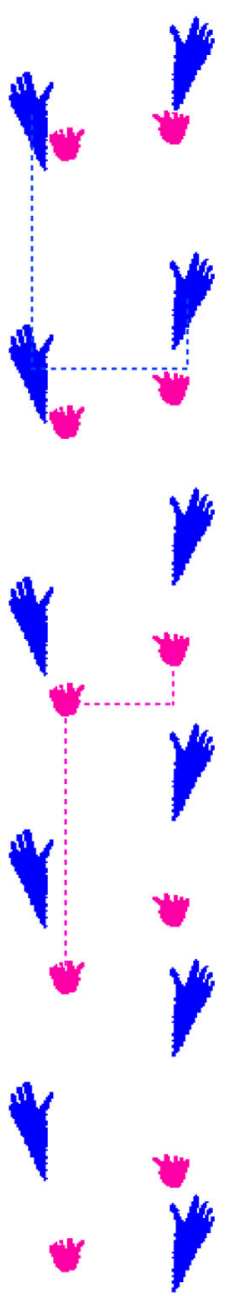
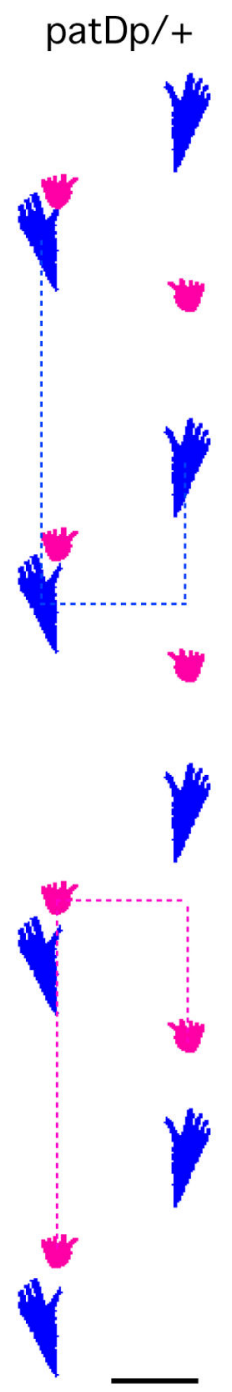

b

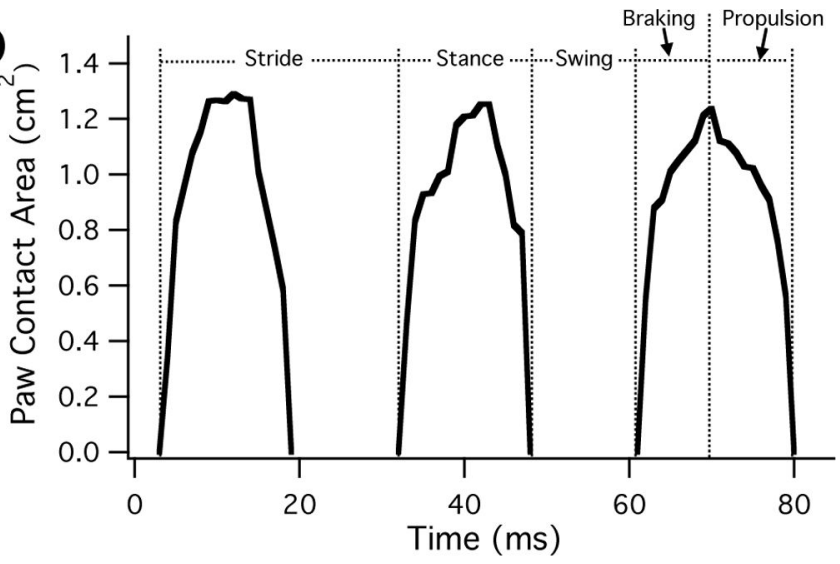

C

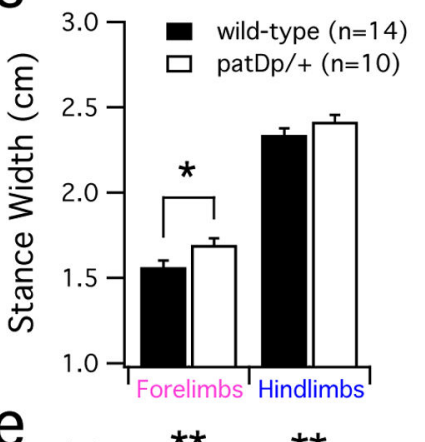

d
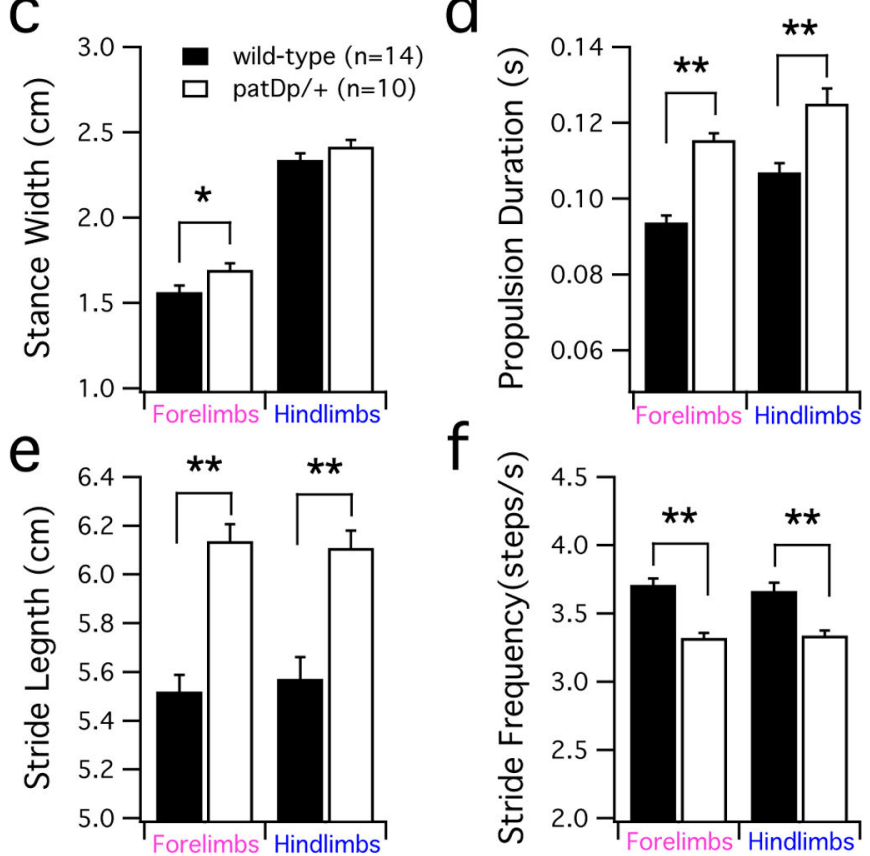

$f$

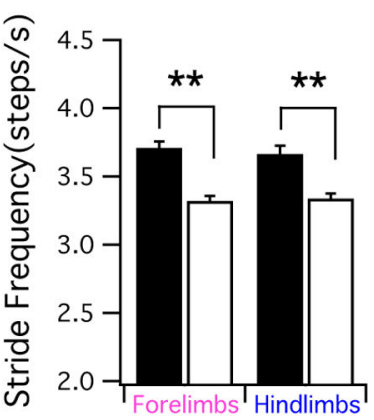

Figure 2. Motor coordination is impaired in patDp/+ mice

(a) Example paw prints acquired during locomotion on a DigiGait treadmill at a running speed of $20 \mathrm{~cm} / \mathrm{s}$. Bold dashed lines indicate the stride length and stance width for both the hindpaws (blue) and forepaws (pink). Scale bar $=1 \mathrm{~cm}$. (b) Example trace of a wild-type mouse paw showing the paw contact area over the course of multiple steps. The stride of a paw can be separated into stance and swing phases. Stance phase (the time the paw is in contact with the ground) is further separated into breaking and propulsion phases, occurring before and after the time of maximal paw contact, respectively. (c-f) Bar graphs showing differences in stance width and stride parameters between patDp/+ $(n=10)$ and wild-type mice ( $\mathrm{n}=14$; unpaired Student's $\mathrm{t}$ test; *indicates $\mathrm{p}<0.05$; **indicates $\mathrm{p}<0.01$; see also Supplementary Table 1). Displayed are the stance width $(\mathbf{c})$, the propulsion duration $(\mathbf{d})$, the stride length (e), and the stride frequency (f). Values are shown as mean \pm SEM. 
a

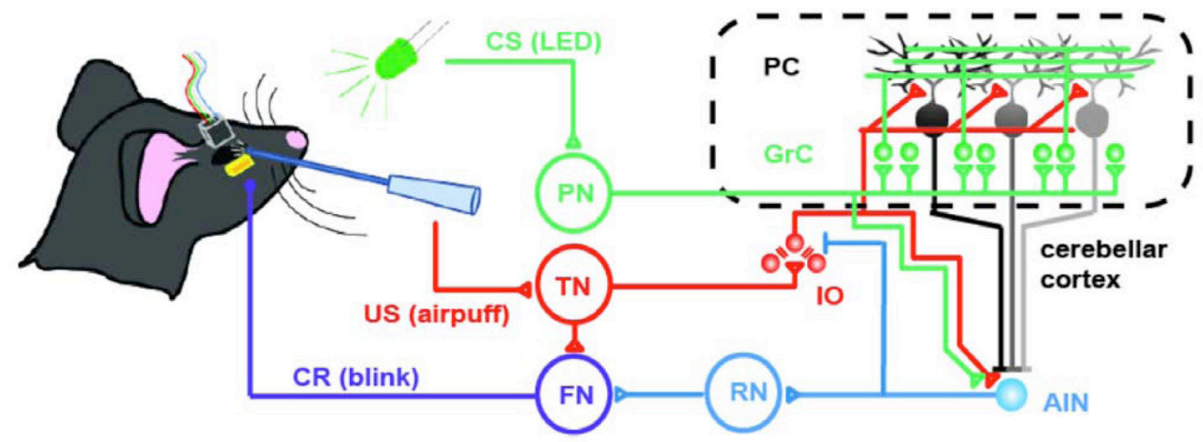

b
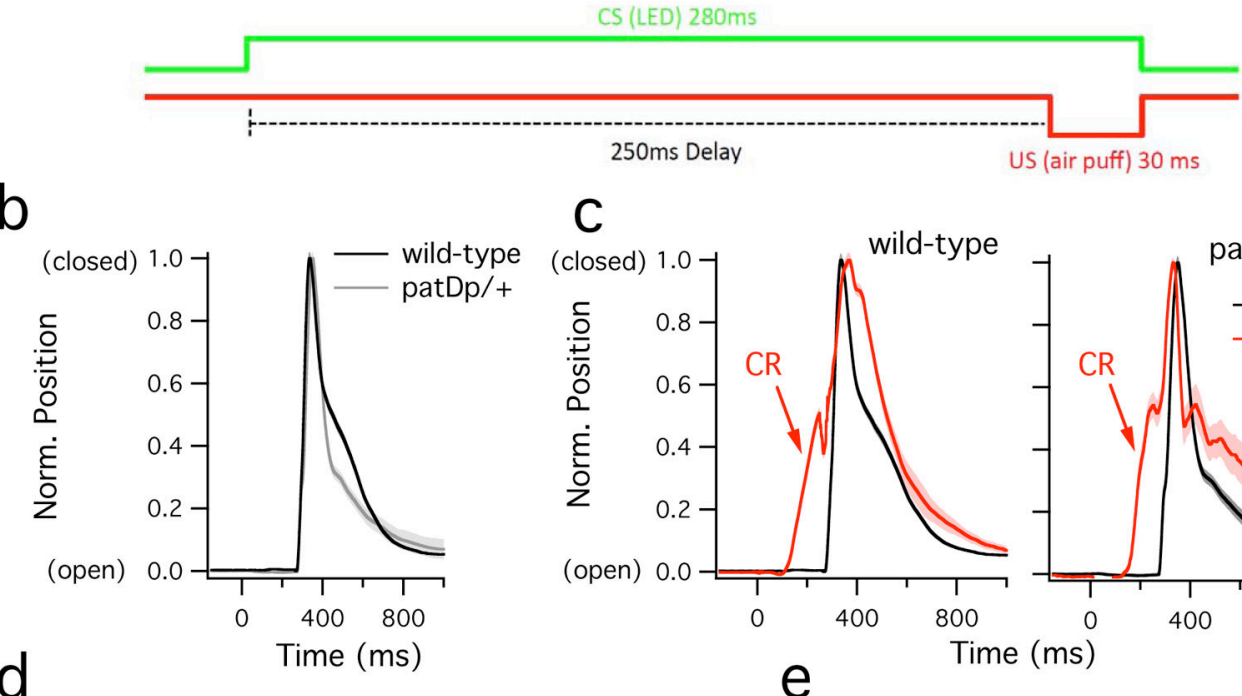

C
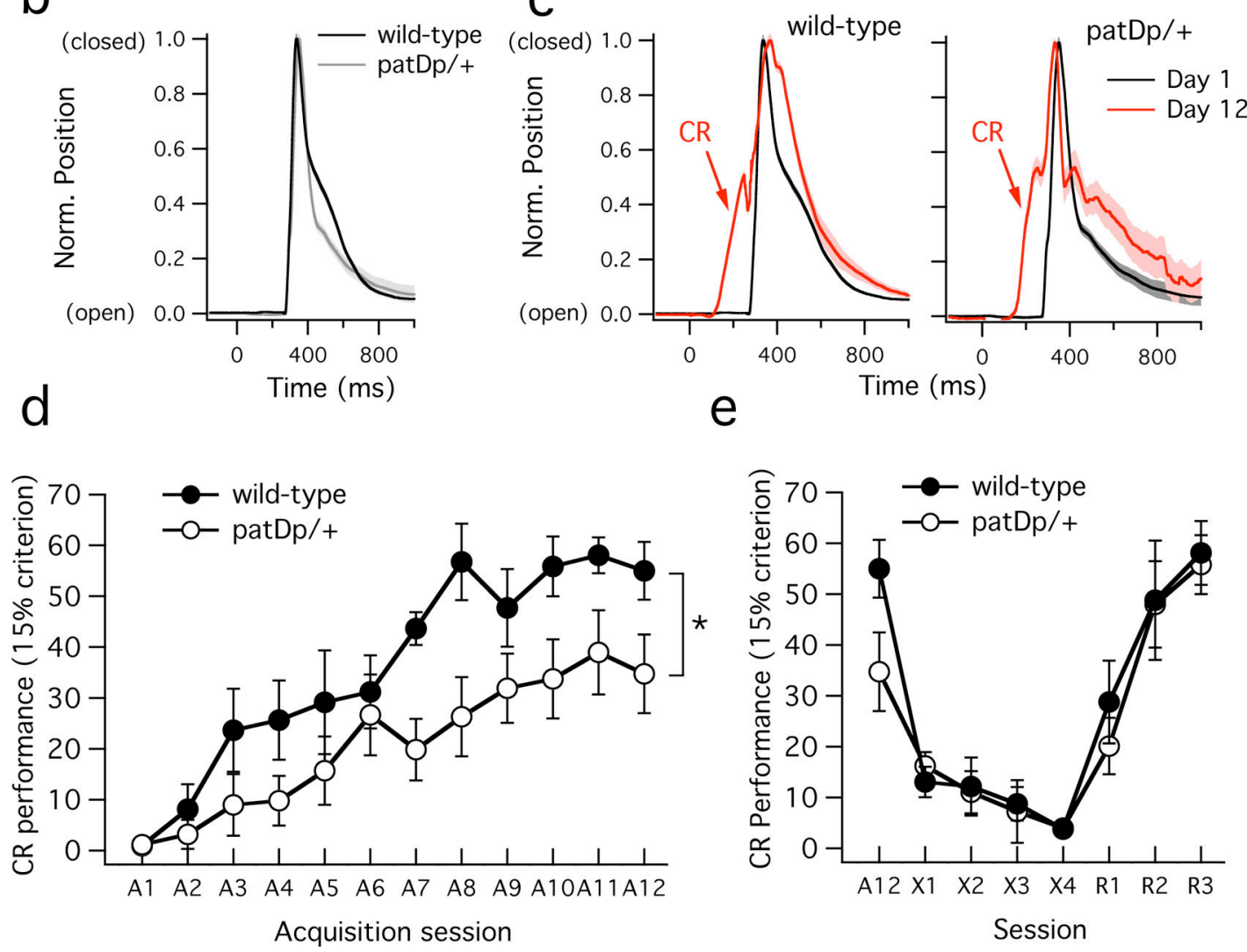

Figure 3. Delay eyeblink conditioning is impaired in patDp/+ mice

(a) Top: Neural circuitry involved. The conditioned stimulus (CS) pathway is shown in green, the unconditioned stimulus (US) pathway in red, and the conditioned response (CR) pathway in blue. PN: pontine nuclei; GrC: granule cells; PC: Purkinje cells; IO: inferior olive; AIN: anterior interposed nucleus; TN: trigeminal nucleus; RN: red nucleus; FN: facial nucleus. CR production results when the CS is paired with a co-terminating US, possibly through long-term depression (LTD) at GrC (parallel fiber) to PC synapses, resulting in AIN disinhibition. Bottom: conditioning protocol showing the 280ms CS (LED) followed after 
$250 \mathrm{~ms}$ by the $30 \mathrm{~ms}$ US (airpuff). (b) and (c) UR and CR traces. Note that $\mathrm{t}=0 \mathrm{~ms}$ corresponds to the CS onset (see protocol in A). (b) Typical eyelid closure during the UR (triggered by the US at $\mathrm{t}=250 \mathrm{~ms}$ ) in recordings from a WT mouse (black trace) and a patDp/+ mouse (gray trace). (c) Typical traces showing the CR/UR after CS-US pairing at day 1 (black) and the CR at day 12 (red) in a WT mouse (left) and a patDp/+ mouse (right). CR traces look similar in patDp/+ mice, but occur at a lower success rate. (d) Time graph showing CR acquisition (\% occurrence) during sessions A1-12 in WT $(n=11)$ and patDp/+ mice $(\mathrm{n}=10)$. A repeated-measures two-way ANOVA indicates a significant effect of genotype $\left(\mathrm{F}_{1,209}=18.94 ; \mathrm{p}=0.0003\right)$ and of time $\left(\mathrm{F}_{11,209}=19.43 ; \mathrm{p}=4 \times 10^{-13}\right)$ with no significant interaction $\left(\mathrm{F}_{11,209}=1.54 ; \mathrm{p}=0.1179\right)$. (e) $\mathrm{CR}$ performance during extinction sessions X1-4 and reacquisition sessions R1-3. Repeated-measures two-way ANOVAs show no significant effect of genotype on extinction and reacquisition over time (extinction: $\mathrm{F}_{1,51}=0.04 ; \mathrm{p}=0.8390$; reacquisition: $\mathrm{F}_{1,34}=0.42 ; \mathrm{p}=0.5248$ ) with a significant effect of time (extinction: $\mathrm{F}_{3,51}=7.61 ; \mathrm{p}=0.0003$; reacquisition: $\mathrm{F}_{2,34}=13.06 ; \mathrm{p}=0.0001$ ), but no interaction (extinction: $\mathrm{F}_{3,51}=0.33 ; \mathrm{p}=0.8019$; reacquisition: $\mathrm{F}_{2,34}=0.18 ; \mathrm{p}=0.8395$ ). Error bars are \pm SEM. *indicates $\mathrm{p}<0.05$. 
a

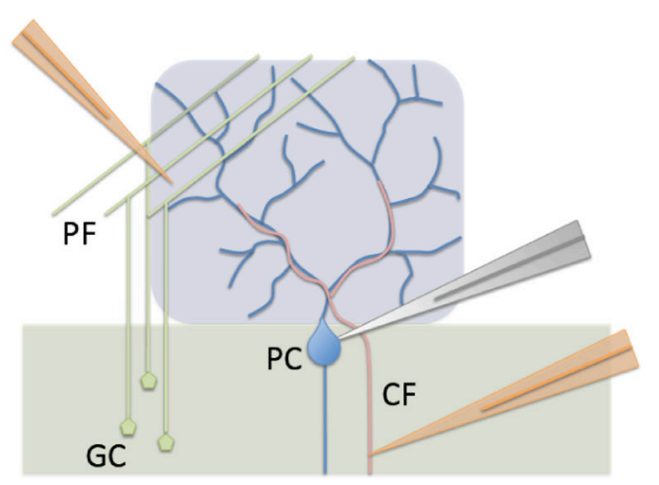

b
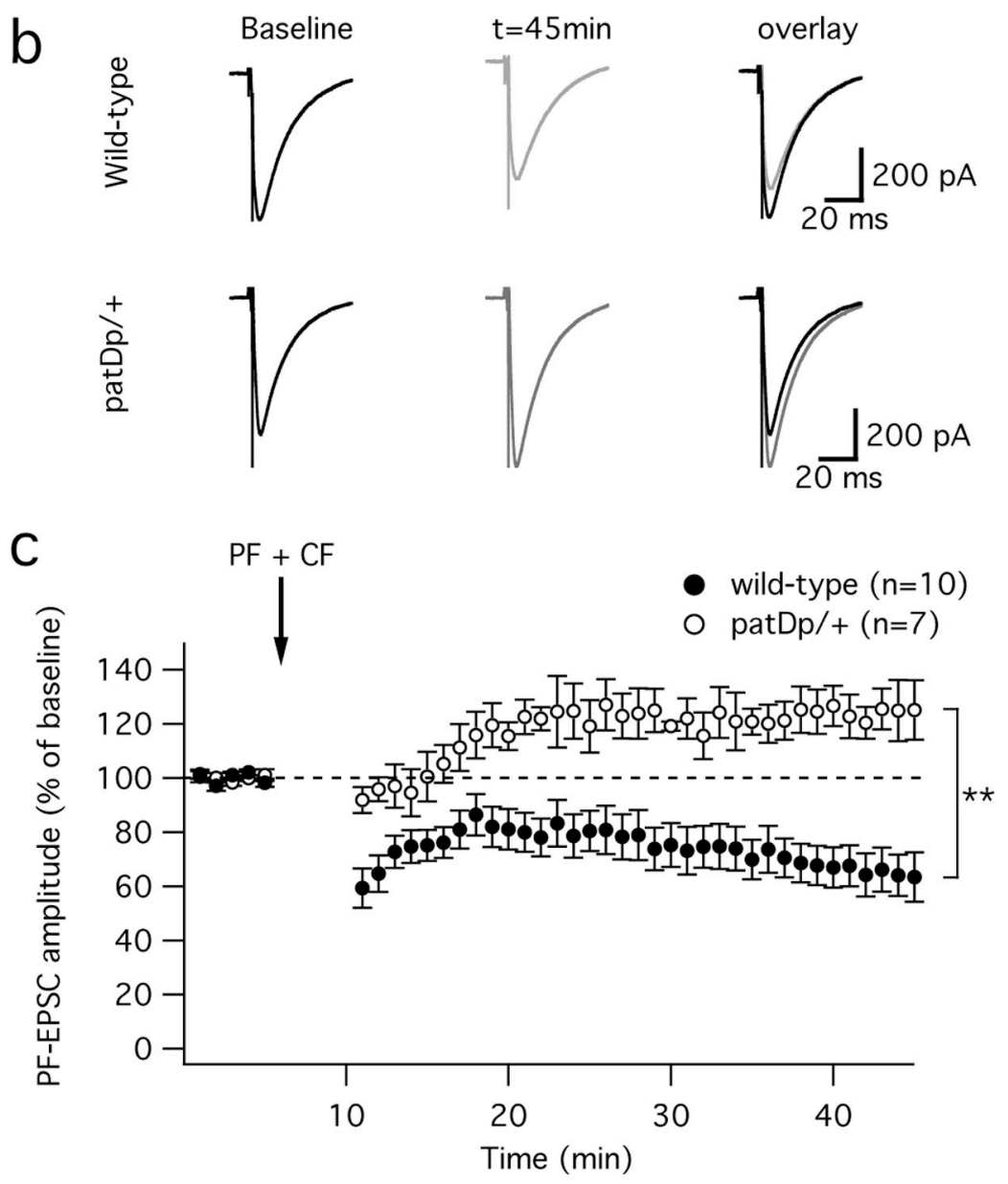

Figure 4. PF-LTD is impaired in patDp/+ mice

(a) Scheme of the recording configuration used to examine LTD at PF-Purkinje cell synapses in cerebellar slices. A somatic recording from a Purkinje cell (blue) is performed using a patch pipette (grey). A PF burst ( 8 pulses at $100 \mathrm{~Hz}$ ) is applied by a stimulation electrode (orange, left) placed in the molecular layer. The CF input is activated $120 \mathrm{~ms}$ after PF stimulus onset by a second stimulation electrode (orange, right) placed in the granule cell layer. (b) Typical PF-EPSC traces before and after application of the tetanization protocol. PF-LTD is induced in wild-type mice (top), but is absent from patDp/+ mice (bottom). (c) 
Time graph showing LTD at PF-Purkinje cell synapses in wild-type mice ( $\mathrm{n}=10$; paired Student's $\mathrm{t}$ test; $\mathrm{p}=0.0009)$ and a potentiation resulting from the same tetanization in $\mathrm{patDp} /+$ mice ( $\mathrm{n}=7$; paired Student's $\mathrm{t}$ test; $\mathrm{p}=0.026$ ). The difference between both groups is significant (Mann-Whitney $\mathrm{U}$ test; $\mathrm{p}=0.0011$ ). The arrow indicates the time point of tetanization. Error bars are mean \pm SEM. $* *$ indicates $\mathrm{p}<0.01$. 
a

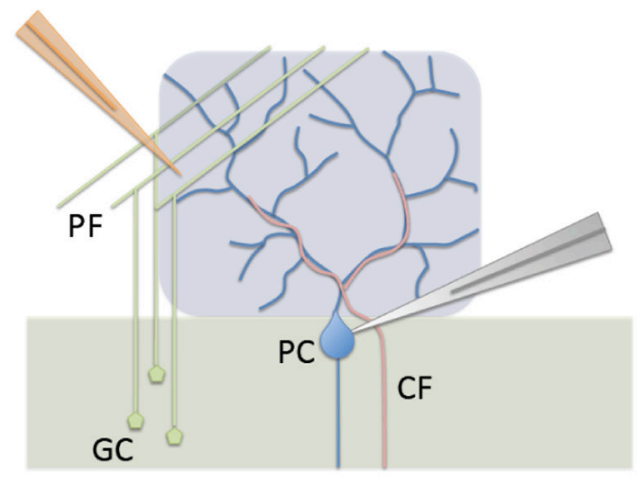

b
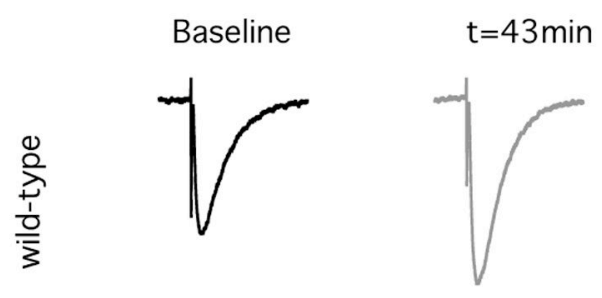

overlay
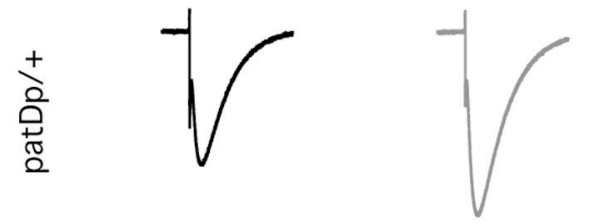

C

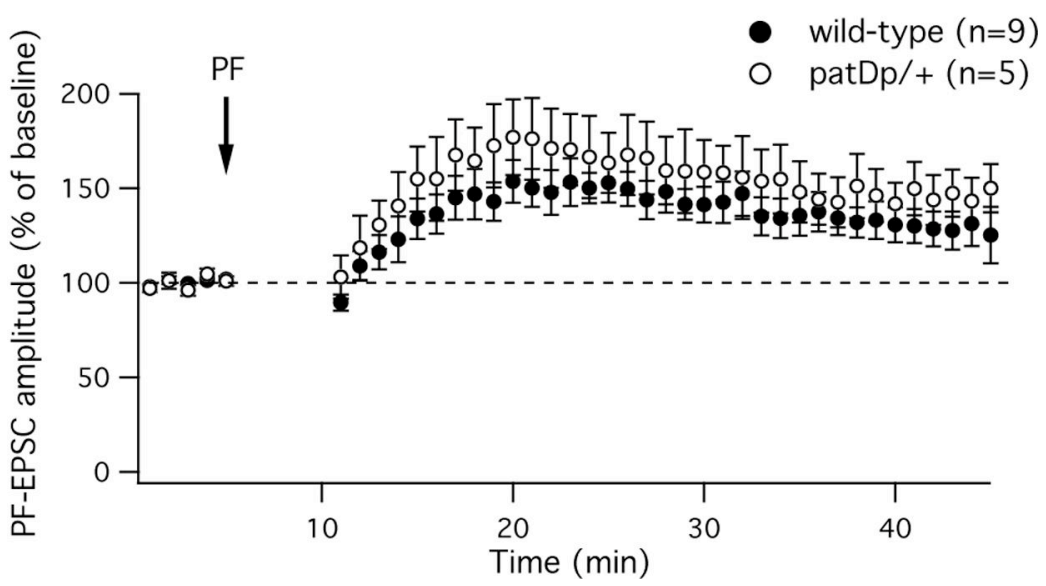

Figure 5. PF-LTP is unaffected in patDp/+ mice

(a) Recording configuration. A somatic recording from a Purkinje cell (blue) is performed using a patch pipette (grey). PF burst stimulation ( 8 pulses at $100 \mathrm{~Hz}$ ) is applied through a stimulus electrode (orange) placed in the molecular layer. The PF burst is activated at $1 \mathrm{~Hz}$ for 5min. (b) Typical PF-EPSCs recorded during the baseline and after application of the LTP protocol. PF-LTP is observed in wild-type mice (top) and in patDp/+ mice (bottom). (c) Time graph showing LTP at PF-Purkinje cell synapses in slices prepared from wild-type $(\mathrm{n}=9$; paired Student's t test; $\mathrm{p}=0.017)$ and $\mathrm{patDp} /+$ mice $(\mathrm{n}=5$; paired Student's $\mathrm{t}$ test; 
$\mathrm{p}=0.02$ ). There is no significant difference between both groups (Mann-Whitney $\mathrm{U}$ test; $\mathrm{p}=0.28$ ). The arrow indicates the time point of tetanization. Error bars are mean $\pm \mathrm{SEM}$. 


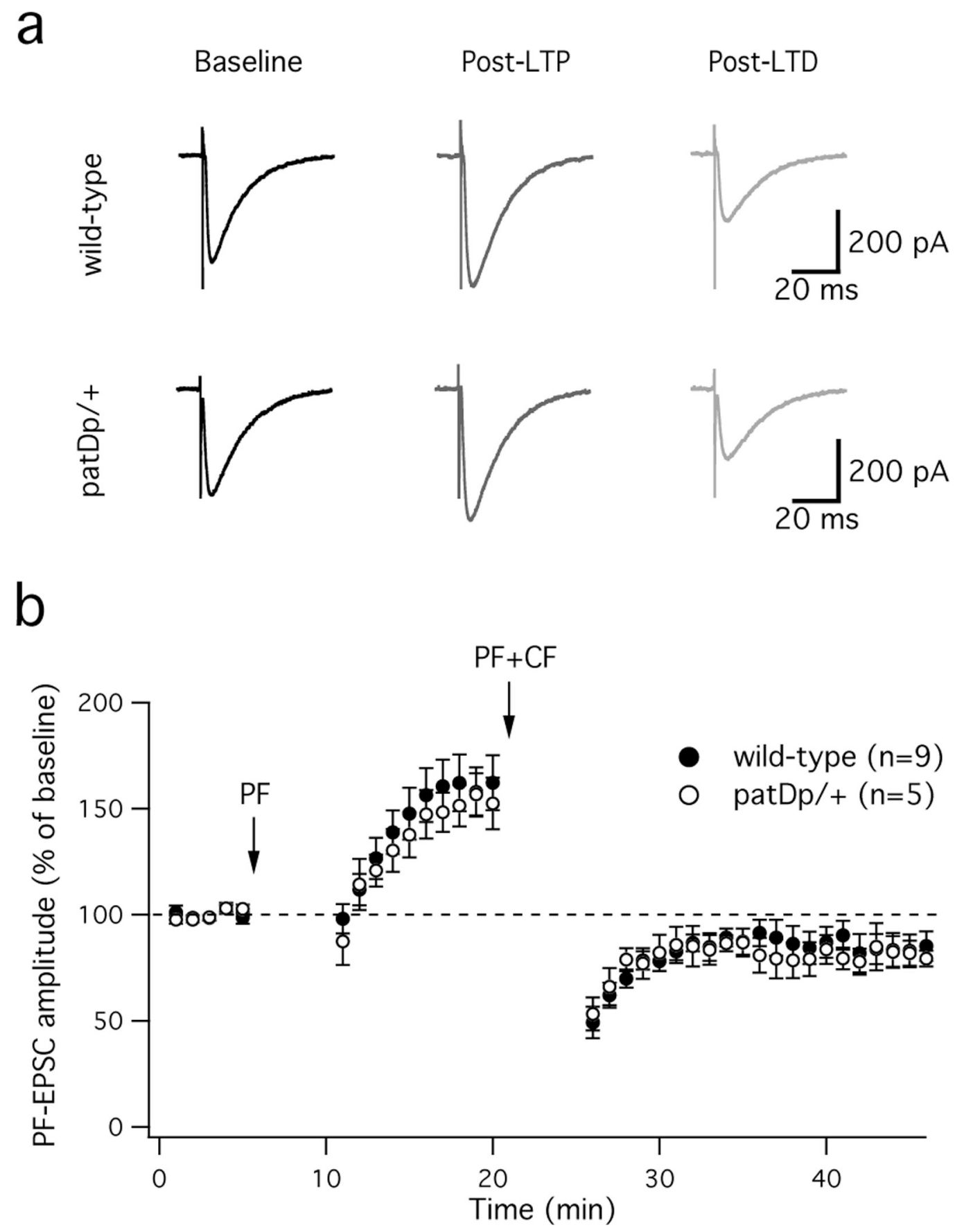

Figure 6. LTD is restored after prior LTP induction

(a) Typical PF-EPSCs recorded during the baseline, after application of the LTP protocol, and after subsequent application of the LTD protocol. PF-LTP followed by LTD was observed in both wild-type mice (top) and patDp/+ mice (bottom). (b) Time graph showing LTP followed by LTD in wild-type mice ( $n=9$; paired Student's t test; LTP: $p=0.0014$; LTD: $\mathrm{p}=0.04$ ) and patDp/+ mice ( $\mathrm{n}=5$; paired Student's t test; LTP: $\mathrm{p}=0.008$; LTD: $\mathrm{p}=0.04)$. There is no significant difference (Mann-Whitney $U$ test) in LTP $(p=0.69)$ and LTD amplitudes 
$(\mathrm{p}=0.89)$ between both groups. The arrows indicate the time points of tetanization. Error bars are mean \pm SEM. 
a
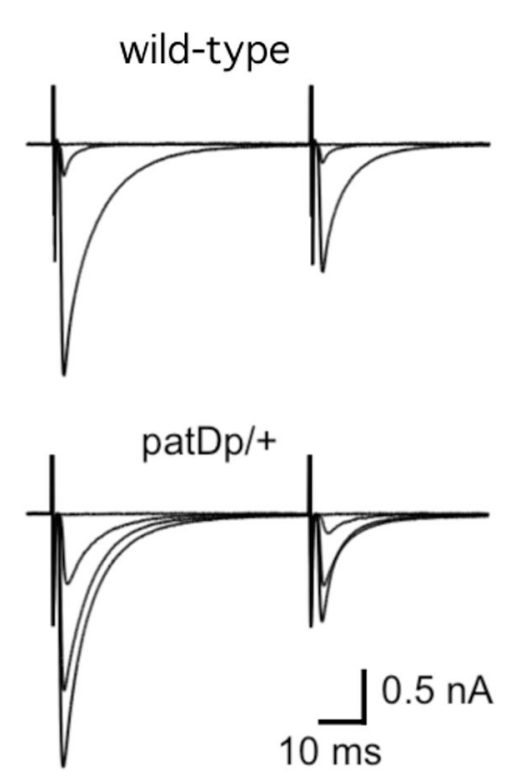

C

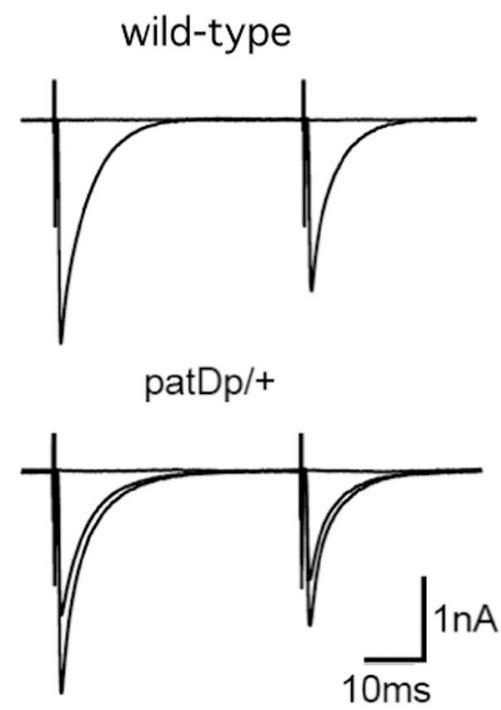

b

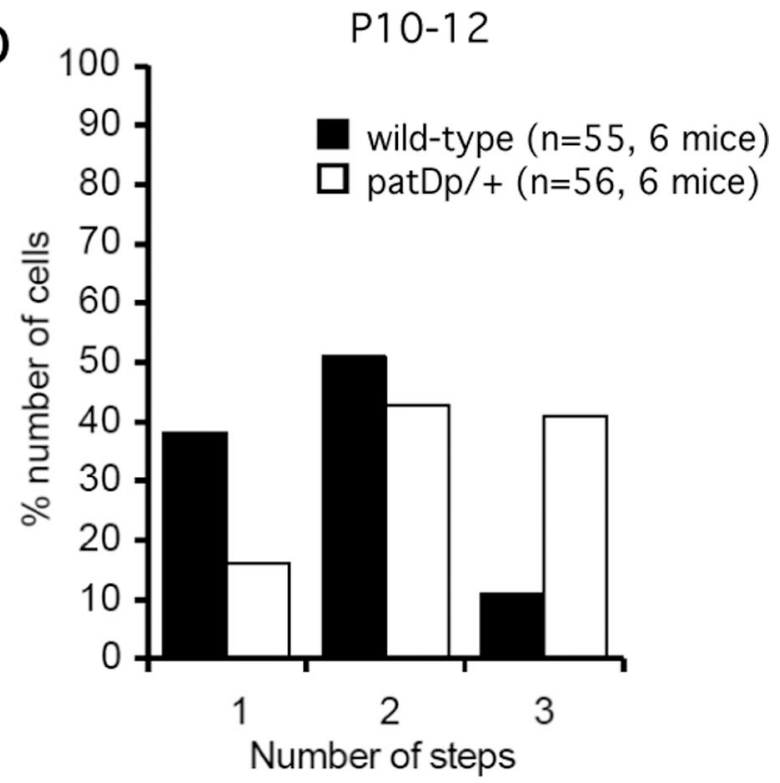

d

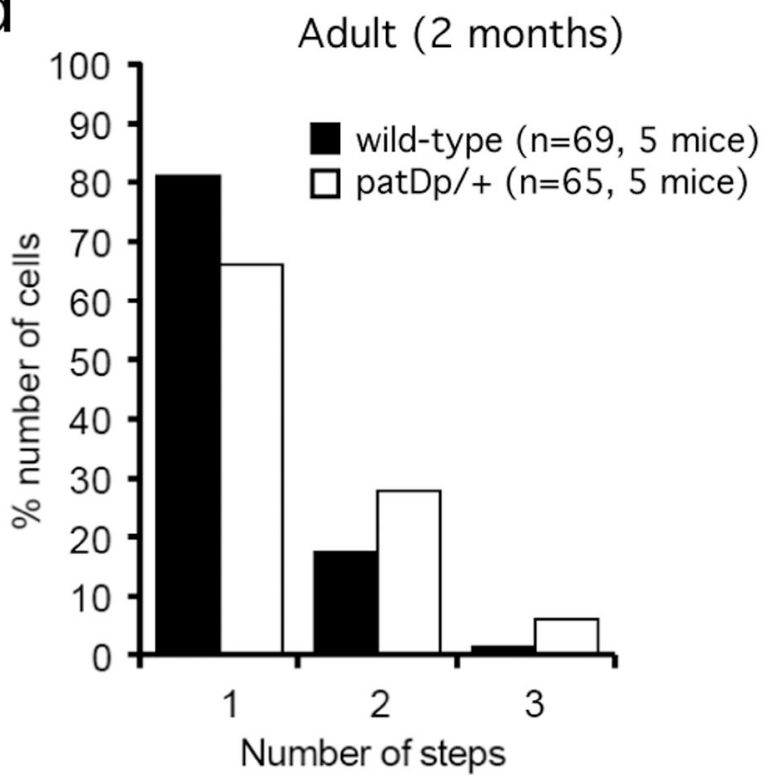

Figure 7. The developmental elimination of surplus CFs is impaired in patDp/+ mice (a) Typical traces showing discrete CF-EPSC steps in slices prepared from a P11 wild-type mouse (top) and a P11 patDp/+ mouse (bottom). In all recordings, the holding potential was set to $\mathrm{Vm}=-10 \mathrm{mV}$. (b) Bar graph displaying the percentage of P10-12 wild-type ( $\mathrm{n}=55$ from 6 mice) and patDp/+ ( $n=56$ from 6 mice) Purkinje cells showing one, two, and three discrete CF-EPSC steps, which are taken as a measure of the number of CF inputs. The CF input distribution is significantly different between both groups (Mann-Whitney U test; $\mathrm{p}=0.003$ ). (c) Typical recordings obtained from a P67 wild-type (top) and a P69 patDp/+ mouse 
(bottom). (d) Bar graph showing the percentage of P63-70 wild-type ( $\mathrm{n}=69$; from 5 mice) and patDp/+ ( $\mathrm{n}=65$ from 5 mice) Purkinje cells showing one, two and three CF-EPSC steps. In the adult group the $\mathrm{CF}$ input distribution is also significantly different between both groups (Mann-Whitney $\mathrm{U}$ test; $\mathrm{p}=0.041$ ). 